\title{
Modo Daltônico: plataforma para refletir sobre a inclusão de pessoas com daltonismo no desenvolvimento de interfaces digitais
}

Colorblind Mode: Platform to raise awareness on the inclusion of color blind people on digital interfaces

Alice Santana Almeida ${ }^{[1]}$, Melissa Pozatti ${ }^{[2]}$, Augusto Gowert Tavares $^{[3]}$

\begin{abstract}
Resumo: Estima-se que, na população mundial, 770 milhões de pessoas possuam daltonismo. Com os avanços das tecnologias e o uso frequente das mídias digitais, é fundamental considerar a inclusão e o bem-estar deste público ao utilizar estas ferramentas. $\mathrm{O}$ objetivo deste trabalho foi desenvolver uma plataforma que provoque a reflexão acerca da inclusão de usuários daltônicos na projetação de interfaces digitais. Para isto, foi realizada revisão bibliográfica, bem como entrevistas com pessoas que possuem daltonismo a fim de reconhecer as barreiras que estes enfrentam. Através da metodologia design thinking foi construído uma landing page para informar e trazer visibilidade à deficiência visual. Ao final, a plataforma foi testada por pessoas do público-alvo para avaliar sua pertinência.

Palavras-chave: Daltonismo. Design inclusivo. Interfaces digitais. Design thinking.
\end{abstract}


Abstract: Within the the world population, approximately 770 million people are color blind. Considering the advances of technology and the frequent use of digital media, the inclusion and wellbeing of this audience is key when using these tools. Then, this essay's main objective is to develop a platform to raise awareness about the inclusion of colorblind users in digital interfaces design. For this, a literature review was carried out, as well as interviews with color blind people in order to recognize the barriers they face. Through the design thinking methodology, a landing page was built to inform and bring visibility to visual impairment. In the end, the platform was tested by people from the target audience to evaluate its relevance.

Keywords: Colorblind. Inclusive design. Digital interfaces. Design thinking.

\section{INTRODUÇÃO}

De acordo com Norman (2008), é papel do designer pensar e construir produtos, sejam eles quaisquer, que possam ser utilizados pela maioria da população, independente do seu perfil ou condição. Nesse sentido, o design inclusivo é uma das áreas de projeto que busca considerar a existência de diferentes usuários com necessidades específicas que mudam ou não ao longo da vida, podendo estas serem limitações permanentes, temporárias ou momentâneas (GOMES; QUARESMA, 2016). Dentre as limitações permanentes, existe a discromatopsia (daltonismo), uma deficiência visual que afeta a percepção das cores e que não possui cura. Embora no Brasil não haja dados oficiais atualizados acerca desse tema, estima-se que na população mundial o daltonismo atinge de $6 \%$ a $10 \%$ dos homens e 0,4\% a 0,7\% das mulheres. (GORDON, 1998).

Enquanto uma pessoa com visão considerada normal consegue visualizar até 30 mil cores, um daltônico identifica de 500 a 800 cores (LIMA, 2015). Por conta disso, pessoas com daltonismo enfrentam uma série de dificuldades ao realizar tarefas e utilizar produtos que exijam o reconhecimento de determinadas cores, ocasionando, muitas vezes, desconforto psicológico (LIMA, 2015). Villon (2019) discorre sobre a importância das cores para as muitas interações, inclusive no meio digital, e aponta que para proporcionar comunicações inclusivas e acessíveis para usuários daltônicos é necessário que os profissionais da comunicação os levem em consideração como público. Frente a isso, como trabalho de conclusão de 
curso, projetou-se uma plataforma com o objetivo de provocar o debate e a reflexão acerca da inclusão de usuários daltônicos no processo de desenvolvimento de interfaces digitais. Para realização do trabalho utilizou-se a metodologia de design thinking do Instituto de Design de Stanford (2018) em conjunto com a metodologia da Escola de Design Thinking (2016). O estudo envolveu a identificação do público-alvo e de suas principais demandas e dificuldades, familiarização com os conceitos de design relacionados ao design de interfaces, design inclusivo e design da informação e o desenvolvimento de uma interface com escopo definido, a partir de telas em wireframes ${ }^{[3]}$. O projeto não contemplou a implementação da plataforma, uma vez que não possuiu duração suficiente para o desenvolvimento do produto final. Contudo, um protótipo navegável de alta fidelidade foi desenvolvido na plataforma Figma ${ }^{[4]}$ $e$ testado com 3 usuários. O presente artigo visa apresentar o processo de desenvolvimento do projeto, bem como seus resultados, e divide-se em três partes principais: fundamentação teórica, metodologia projetual e desenvolvimento prático.
[3] Esqueleto de mapeamento dos elementos de uma página da web.

[4] Ferramenta de design de interface gratuita e online, onde é possível prototipar, criar, colaborar e inspecionar.

\section{REFERENCIAL TEÓRICO}

Neste tópico serão apresentados aspectos relativos à fundamentação teórica do estudo, como características de pessoas com deficiência visual, mais especificamente daltônicas, e as dificuldades que estas enfrentam no dia a dia, a utilização do design de interfaces digitais como um meio de comunicação e conceitos do design da informação e do design inclusivo.

\subsection{DALTONISMO (DISCROMATOPSIA)}

A Lei n. 13.146, de 2015 (BRASIL, 2018), popularmente conhecida como Lei Brasileira de Inclusão (LBI), capítulo 1, art. $2^{\circ}$ considera pessoa com deficiência aquela que:

[...] Tem impedimento de longo prazo de natureza física, mental, intelectual ou sensorial, o qual, em interação com uma ou mais barreiras, pode obstruir sua participação plena e efetiva na sociedade em igualdade de condições com as demais pessoas (BRASIL, 2018). 
Dentre as deficiências existentes está a deficiência visual (DV), que consiste no comprometimento parcial ou total da visão, ocasionada pelo mau funcionamento do sistema visual. Existem diversos aspectos que podem prejudicar a visão a longo prazo, como a senilidade, acidentes ou doenças. Um dos tipos de deficiência visual é a discromatopsia, popularmente conhecida como daltonismo. Essa deficiência normalmente é congênita ${ }^{[5]}$, mas pode ser adquirida através de alguma doença que afeta o nervo óptico. Trata-se de um distúrbio na visão das cores que provoca um grande impacto e gera dificuldades em diferentes fases da vida destes que possuem (ANDRADE; PINTO; SILVA, 2017).

O daltonismo é uma deficiência visual ocasionada por uma alteração genética que se caracteriza pela incapacidade de percepção da cor (FARINA; RODRIGUES; FILHO, 2006). A organização Colour Blind Awareness (2014) aponta que existem aproximadamente 300 milhões de pessoas com discromatopsia no mundo, e estima que afeta cerca de 1 a cada 12 homens (8\%) e 1 a cada 200 mulheres da população mundial. Esta anomalia não tem cura e ocorre quando existe a ausência ou insuficiência dos cones, células fotossensíveis responsáveis pela visão da cor, do espaço e da acuidade visual (IIDA, 2005). Os cones possuem uma variedade de pigmentos fotossensíveis e cada um possui um espectro de sensibilidade diferente - existem os cones sensíveis ao vermelho, ao verde e ao azul (BRUNI; CRUZ, 2006).

Segundo Maia (2006), um dos tipos de daltonismo mais conhecido é a tricromacia anormal, na qual existe a presença dos três tipos de cones, porém, um deles apresenta alteração de um dos pigmentos (verde, vermelho ou azul). O tricromatismo anômalo ocorre em diferentes graus: existe a protanomalia (dificulta a percepção da cor vermelha), a deuteranomalia (verde), e a tritanomalia (azul e amarelo), sendo este último o mais incomum (FARINA; RODRIGUES; FILHO, 2006). Outro tipo de daltonismo é a dicromacia, que consiste na presença de apenas dois cones, o que ocasiona
[5] Condição física presente desde o nascimento. 
na ausência ou na complexidade de assemelhação de uma das cores. O dicromatismo pode variar entre protanopia (vermelho) e deuteranopia (verde), sendo estes os mais frequentes, e a tritanopia (azul e amarelo) (BRUNI E CRUZ, 2006). E, por fim, a monocromacia, um dos tipos mais raros de deficiência visual às cores, a qual se limita somente a um cone e incapacita a pessoa de reconhecer todas as cores, percebendo-as somente em tons de cinza (MAIA, 2013). Na figura 1 é possível visualizar como cada tipo de daltonismo afeta na visualização das cores.

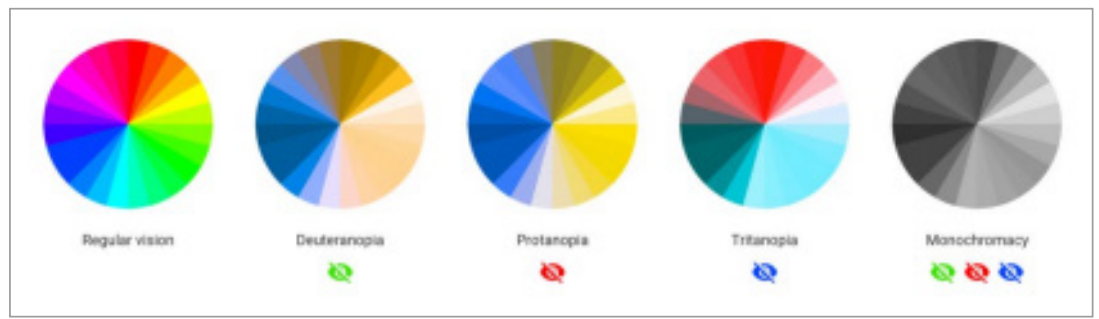

Por razão da pouca visibilidade que pessoas com deficiência possuem e devido a falta de recursos, estas necessitam se adaptar individualmente para diminuir as dificuldades do cotidiano e suprir as suas necessidades em ambientes públicos (AMPHILÓQUIO; SOBRAL, 2018).

A Colour Blind Awareness (2021) relata que pessoas com daltonismo possuem dificuldade em comprar e preparar comidas, principalmente pessoas com deficiências relacionadas à visão do verde ou vermelho. Elas desenvolvem estratégias para comprar frutas e legumes como, por exemplo, aprendem que as maçãs maduras são mais escuras e que geralmente são mais macias que as não maduras. A organização também aborda o problema que o público sofre, principalmente na escola, ao utilizar lápis de cor e, por isso, recomenda aos professores que os lápis sejam etiquetados com o nome da cor. Assim, também será possível compreender quando os trabalhos de alunos com daltonismo apresentarem resultados considerados fora do padrão. Um estudo realizado por Melo, Galon e
Figura 1 - Tipos de daltonismo. Fonte: Color blindness: how to design an accessible user interface (2018). 
Fontanella (2014) com participantes daltônicos, revelou que, para enfrentamento de dificuldades na escola, os daltônicos desenvolveram algumas habilidades, conhecidas como coping skills $s^{[6]}$. Um dos voluntários relatou que organizava os lápis de cor dentro da caixa e decorava a ordem para saber exatamente onde cada cor estava. Já outra pessoa visualizava os números presentes no lápis e verificava atrás da caixa a cor exata.

Na mesma pesquisa (MELO; GALON; FONTANELLA, 2014), participantes daltônicos também relataram as suas adaptações em meio digital. Pessoas que possuem contato com softwares de edição de imagem, como o Photoshop, referiram recorrer aos códigos hexadecimais do programa para compreensão das cores, já que cada uma possui um código único. Outro voluntário desenvolveu o mecanismo de reconhecimento de tons através do sistema de cores aditivas red-green-blue (RGB), onde é possível observar a composição de cada cor. $\mathrm{Na}$ figura 2 é possível ter o entendimento de como o sistema atua:

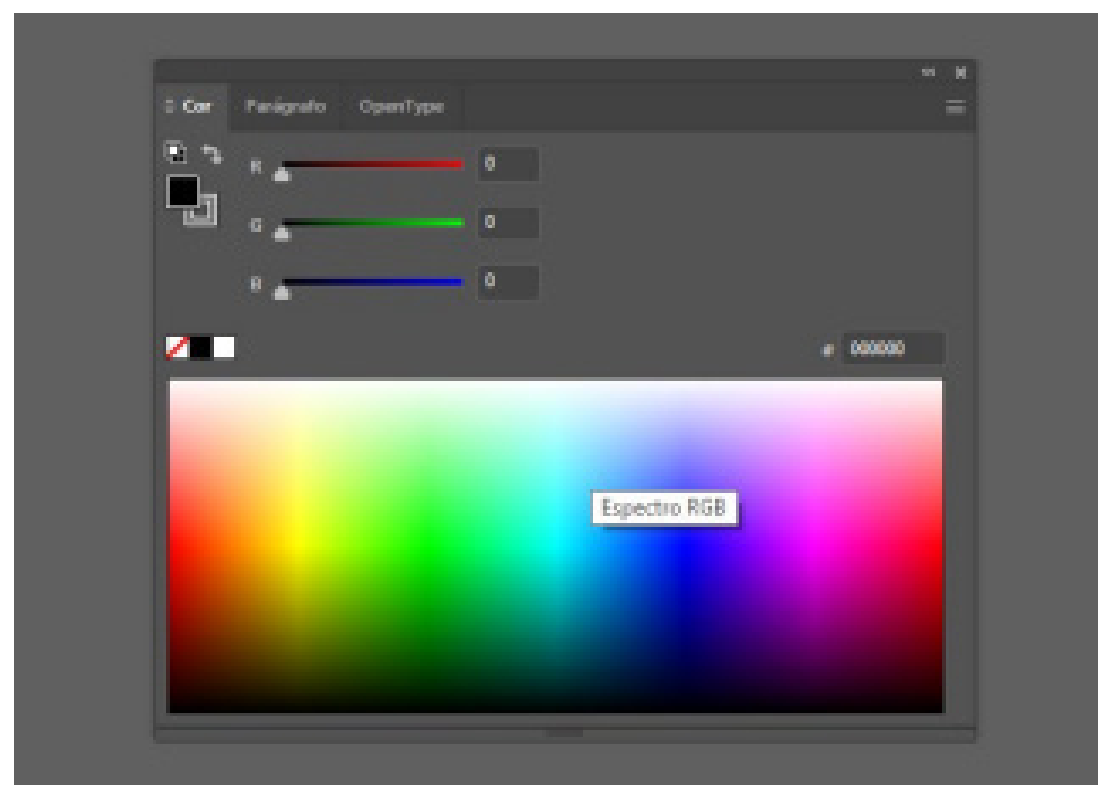

As tecnologias assistivas são importantes para proporcionar qualidade de vida e oferecer autonomia às pessoas com deficiência, promovendo a inclusão social deste grupo.
[6] Conceito da psicologia cognitiva que se caracteriza pelo conjunto de esforços, cognitivos e comportamentais, utilizado com o objetivo de lidar com demandas específicas, internas ou externas, quando seus recursos pessoais excedem.
Figura 2 - Sistema de cores aditivas RGB no Photoshop. Fonte: Captura de tela realizada pela autora (2021). 
O conceito de tecnologia assistiva apresentado pelo Comitê de Ajudas Técnicas (2007) é:

Área do conhecimento, de característica interdisciplinar, que engloba produtos, recursos, metodologias, estratégias, práticas e serviços que objetivam promover a funcionalidade, relacionada à atividade e participação, de pessoas com deficiência, incapacidades ou mobilidade reduzida, visando sua autonomia, independência, qualidade de vida e inclusão social (BRASIL, 2007).

A partir do conceito definido pelo Comitê de Ajudas Técnicas (2007), o Trello é uma ferramenta de gerenciamento de projetos online, disponível para desktop ${ }^{[7]}$ e mobile ${ }^{[8]}$, que agiliza a organização de tarefas através de cartões, e permite a colaboração entre os membros. De acordo com o blog da empresa (2020), eles disponibilizam um modo de acessibilidade para daltonismo que pode ser ativado facilmente nos cartões, sendo esta ferramenta um exemplo de tecnologia assistiva. $\mathrm{Na}$ figura 3 é possível observar que quando o modo é ativado, as etiquetas coloridas continuam com suas cores originais, mas ganham um design único que inclui uma padronagem, facilitando a diferenciação das etiquetas por usuários daltônicos.

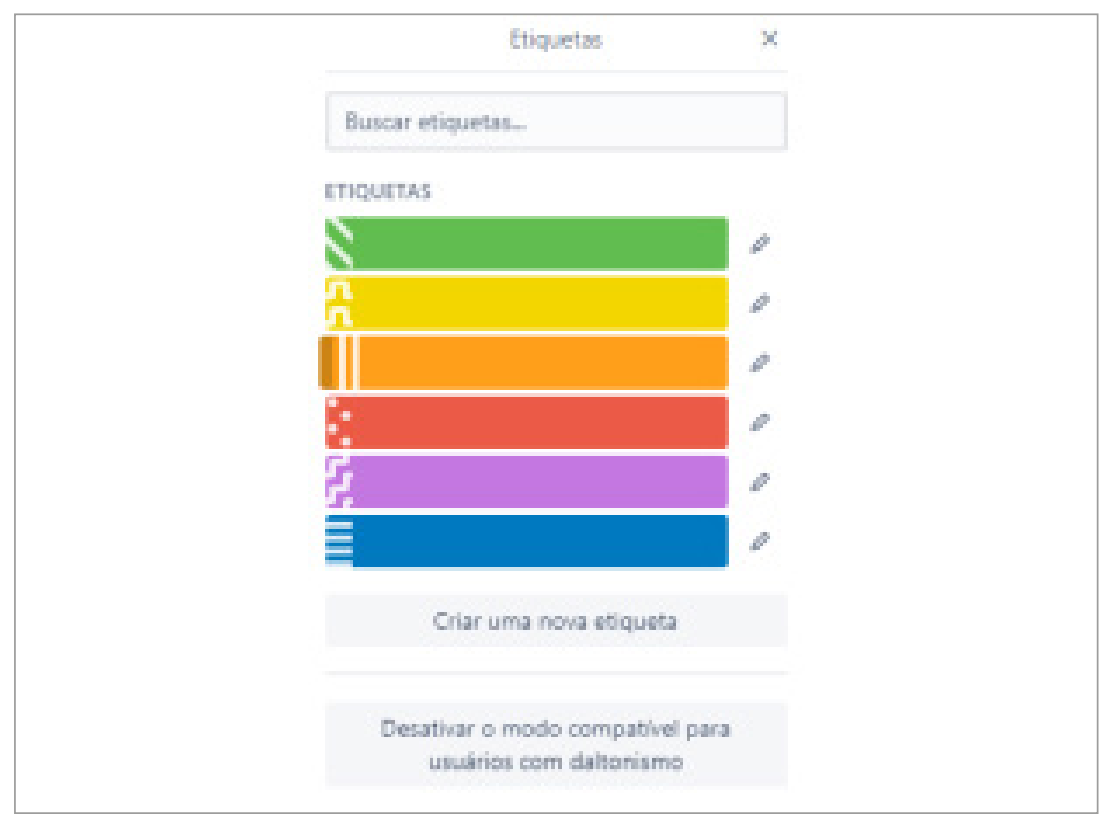

[7] Computador pessoal.

[8] Dispositivo móvel.

Figura 3 - Modo de acessibilidade para daltonismo no Trello. Fonte: Trello (2021). 
Ferramentas como esta disponibilizada pelo Trello incluem usuários com deficiência, proporcionando uma experiência igualitária ao navegar na web. Projetos de interfaces digitais necessitam ser inclusivos para uma parcela da sociedade que está invisibilizada.

\subsection{DESIGN DE INTERFACES DIGITAIS INCLUSIVAS}

O design inclusivo é uma filosofia que tem como finalidade ser utilizada em todo desenvolvimento de projetos de produtos ou serviços, a fim de propiciar a inclusão dos grupos minoritários no processo de seu uso, expandindo e diversificando a integração de usuários ao utilizarem um objeto. Ao adotar esta filosofia, o designer aproxima-se das realidades dos diferentes usuários e busca métodos que proporcionem as mesmas condições a todos. Sendo assim, o objetivo do design inclusivo é desenvolver soluções que beneficiem grupos com limitações, como também aos demais, ampliando o número de usuários que utilizem aquele produto ou serviço (GOMES; QUARESMA, 2016). De acordo com Prates e Barbosa (2007), a interface pode ser definida como:

Parte do sistema computacional com a qual o usuário se comunica, ou seja, aquela com a qual ele entra em contato para disparar as ações desejadas do sistema e receber os resultados destas ações, que o usuário então interpretará, para em seguida definir suas próximas ações. A este processo de comunicação entre usuário e sistema se dá o nome interação (Prates; Barbosa, 2007, p.3).

Para Rogers, Sharp e Preece (2013), o design de interação permite complementar a forma como as pessoas se comunicam e trabalham, expandindo e potencializando as suas experiências e interações com atividades do cotidiano. É uma área que cria produtos interativos a partir da identificação de um problema, utilizando a abordagem de desenvolvimento centrada no humano, que foca em compreender as necessidades dos usuários. Bieling e Joost (2012, online) manifestam que "Ao moldar a interação humana com a tecnologia, o de- 
sign tem o potencial de refletir nos contextos humanos, sociais e organizacionais". Sobre acessibilidade em produtos digitais o website do Windows, sistema operacional, afirma que:

Produtos e serviços - incluindo mídia eletrônica são acessíveis quando são projetados para fornecer experiências completas e bem-sucedidas para o máximo de pessoas possível (MICROSOFT, 2021, online).

O design de informação é uma área do design gráfico que, através do projeto da informação visual, facilita a comunicação. Seu objetivo é transmitir uma mensagem, seja esta composta por palavras, imagens ou sons. Esta informação deve ser construída de forma clara e efetiva, sendo cuidadosamente projetada, produzida e distribuída, para que por fim atraia o usuário e este interprete corretamente o comunicado (PETTERSSON, 2009).

Segundo O'Grady (2008), com a sociedade cada vez mais conectada, a informação tem estado muito presente no meio digital, proporcionando conhecimento para um público mais amplo e ocasionando progressos em direção à acessibilidade, permitindo que muitos grupos se sintam representados. "A demanda por conhecimento universalmente acessível está aumentando em sintonia com o ritmo do mundo moderno" (O'GRADY, 2008, p.8).

\section{METODOLOGIA PROJETUAL}

Neste tópico será apresentada a metodologia utilizada neste trabalho, que dividiu-se em dois momentos: uma primeira parte relativa à contextualização acerca do tema do projeto, a qual denominou-se referencial teórico, e uma segunda parte prática, a qual baseou-se na metodologia de projeto design thinking. Para a parte projetual foram utilizadas duas metodologias de design thinking, o Design Thinking Bootleg do Instituto de Design de Stanford (2018), que se divide em 5 etapas: Empatizar, Definir, Idealizar, Prototipar e Testar, em conjunto com alguns processos presentes no Mini Toolkit de Design 
Thinking da Escola de Design Thinking (2016). Essas duas metodologias foram unidas (figura 4), tendo em vista que ambas têm a abordagem centrada no ser humano e focam nas necessidades e limitações do público definido, sendo adequadas para o contexto deste projeto. Além de gerar produtos com mais valor, o design thinking tem um potencial criativo ágil.

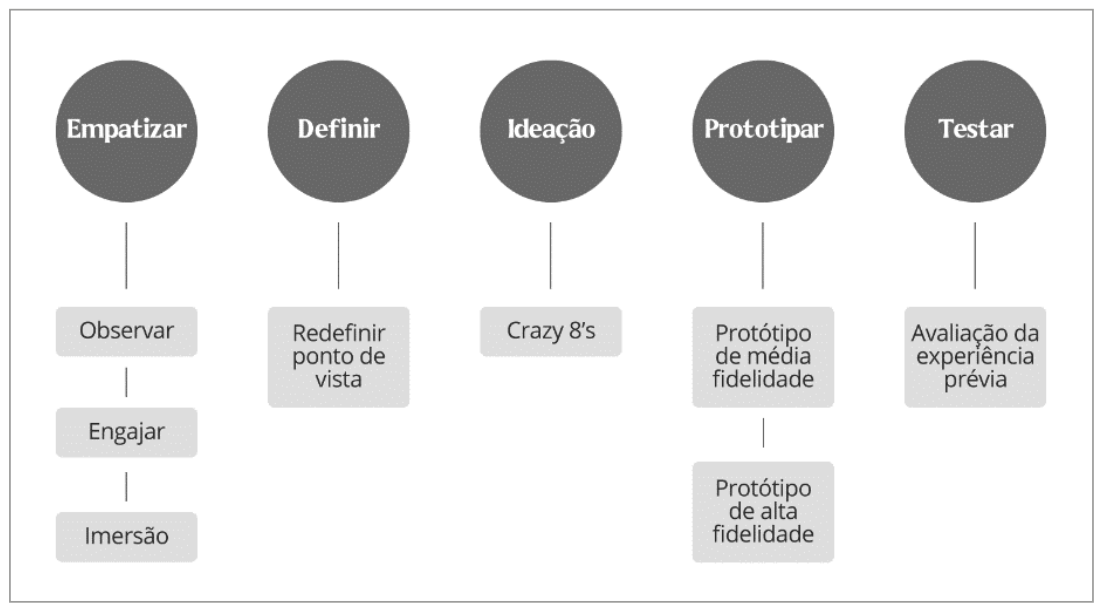

Figura 4-Metodologia projetual. Fonte: Elaborado pela autora (2021).

A primeira etapa da metodologia de projeto consiste em Empatizar com os usuários do projeto, no intuito de reconhecer as suas necessidades e quais são os problemas que eles enfrentam, através do entendimento de seus valores e experiências. Esta etapa inicia-se com o processo de Observar, no qual se observa e se analisa o público em contexto de suas vidas, com o intuito de refletir sobre suas experiências, tentando entender o que pensam e o que precisam. A próxima atividade desta etapa é Engajar, neste momento realiza-se entrevistas e conversas com algumas pessoas relacionadas ao tema do projeto. E por fim, a Imersão, que é o momento de se colocar no lugar do usuário com o objetivo de entender profundamente para quem está se projetando. Neste processo se desenvolve as personas, uma ferramenta de representação fictícia de pessoas referente ao público, e o mapa de empatia. 
Após empatizar com o usuário, ter o entendimento de suas necessidades e observar o seu contexto, a próxima etapa é Definir, onde se reformula o ponto de vista do projeto baseado nas informações coletadas durante a etapa anterior.

A terceira etapa é a Ideação, momento em que se gera uma grande quantidade de alternativas para prototipar. Para isto foi escolhido o Crazy 8's, uma técnica do Design Sprint ${ }^{[9]}$ de realizar 8 esboços em 8 minutos. Em complemento, a quarta etapa visa colocar em prática as ideias reunidas durante a fase de Ideação e Prototipar. Nesse momento se desenvolvem protótipos. E por fim, a última etapa, Testar, na qual foram testados os protótipos com o público e se retorna a refinar o trabalho.

\section{DESENVOLVIMENTO PRÁTICO}

A seguir, serão apresentados o processo do desenvolvimento prático deste trabalho, bem como seus resultados.

\subsection{ETAPA 01 - EMPATIZAR}

Neste momento Observou-se o público daltônico em contexto de suas vidas, através de leituras, entrevista exploratória e de um exercício com a ferramenta matriz CSD. Constatou-se que grande parte destas pessoas se acostumaram a viver com a deficiência, que não possui tratamento ou cura, e desenvolveram mecanismos através dos outros sentidos para viverem de uma maneira mais confortável e prática. Conforme a bibliografia, por se tratar de uma deficiência que não altera a condição física visível para os outros, notou-se que a discromatopsia tem pouca visibilidade na sociedade e que muitas vezes acaba sendo negligenciada.

O segundo processo é Engajar, onde foram feitas algumas anotações e reflexões a partir de entrevista exploratória com um homem daltônico. Se constatou que ele desenvolveu life hacks (adaptações) para viver de maneira mais confortável, como por exemplo, associar as cores a marcas. Ele mencionou o fato de muitas pessoas não terem compreensão da de-
[9] Metodologia ágil, desenvolvida por Jake Knapp, baseada em 4 etapas, Ideação, Construção, Lançamento e Aprendizado. É utilizada em situações onde é necessário o desenvolvimento e a testagem rápida de um produto. 
ficiência e acharem que ele estava inventando, também citou a ocorrência de piadas e brincadeiras ofensivas ao longo de sua vida. Ao utilizar aparelhos eletrônicos, o entrevistado relatou personalizar os elementos do sistema com azul ou com contorno para facilitar a leiturabilidade, utilizar o celular em modo noturno e dar preferência para os fundos de tela mais escuros. Para jogar no computador ele configura o software da placa de vídeo para saturar as cores do jogo, já que os mesmos não possuem um modo compatível para daltônicos.

O terceiro processo desta etapa é a Imersão, no qual realizou-se a criação de duas personas, baseadas no perfil do público-alvo deste trabalho. Na construção da primeira persona, o Pedro (figura 5), destacou-se as seguintes características: Pedro tem 28 anos, é Bacharel em Física, atua como professor e possui daltonismo - tipo deuteranomalia. Ele é didático e se preocupa com o bem estar do coletivo. Gosta bastante de tecnologia, é muito dedicado a estudar sobre qualquer assunto e pensa sobre como colaborar para a sociedade. Seu domínio tecnológico é alto e tem muito interesse em aprender sobre tecnologia.

A segunda persona é a Joana (figura 6), que tem 24 anos, é designer digital e não possui nenhuma deficiência. As características que mais se destacam nela são: Ser uma pessoa comunicável e extrovertida. Gostar de tecnologia e trabalhar como UI/UX ${ }^{[10]}$. Ter habilidades no design digital e auto domínio tecnológico, trabalhar e estudar com tecnologia.

[10] Áreas do design de interfaces digitais.

Ainda na Imersão, foi desenvolvido um mapa de empatia (figura 7) para obter um nível mais profundo de compreensão da persona Pedro, pois era necessário refletir sobre situações e experiências que um usuário com daltonismo vivencia, para assim compreender qual seria o foco da interface.

No mapa de empatia destacou-se que Pedro vê o mundo através do daltonismo - tipo deuteranomalia e que algumas tecnologias não são inclusivas. Escuta as pessoas falando que ele está mentindo a respeito da deficiência, que utiliza isso para não revelar que é burro e também ouve brincadeiras ofensivas 


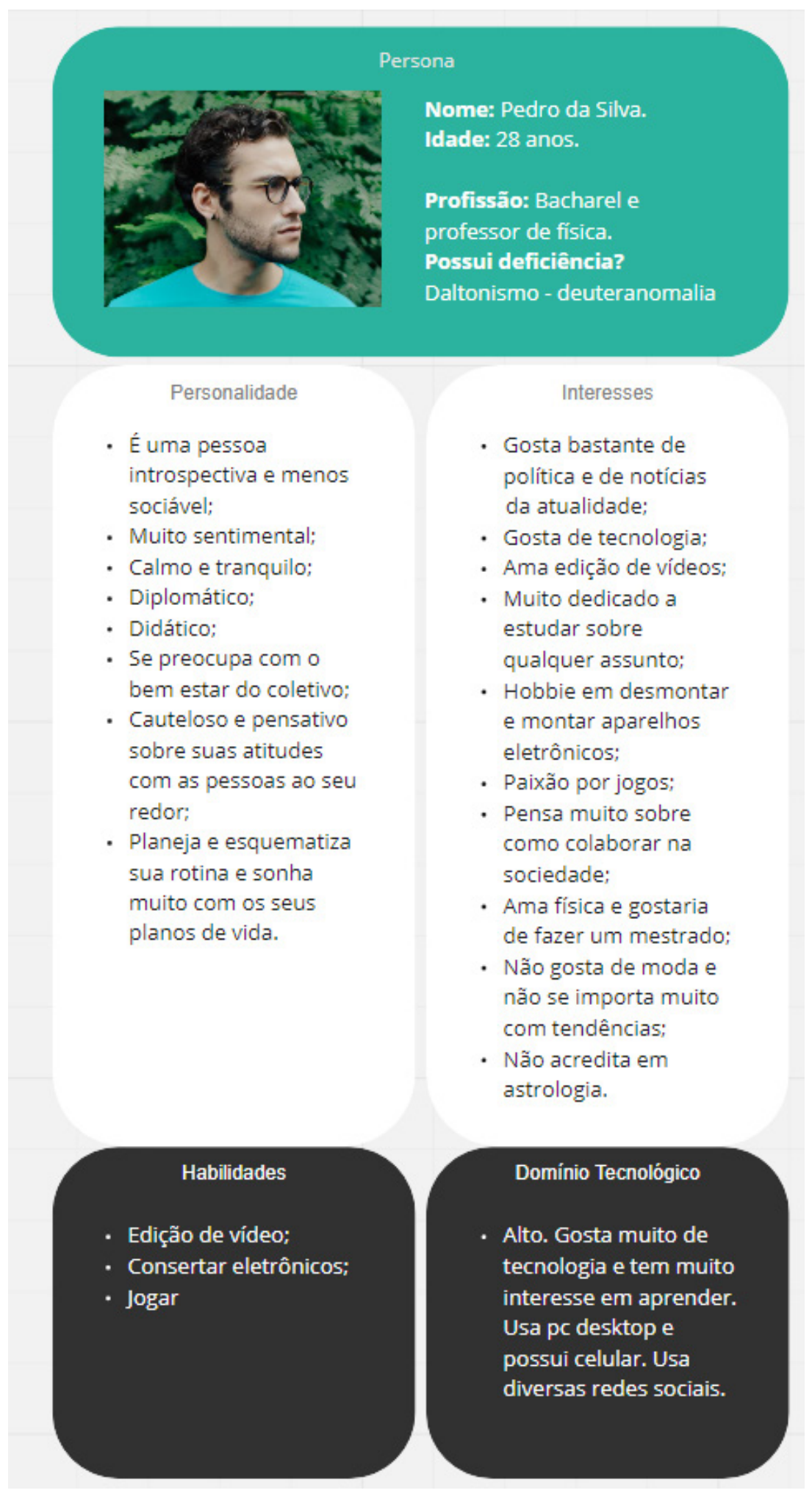

Figura 5 - Empatizar -

Imersão - Persona 1. Fonte:

Elaborado pela autora (2021).

- É uma pessoa

introspectiva e menos sociável;

- Muito sentimental;

Calmo e tranquilo;

Diplomático

Didático

Se preocupa com redor

Planeja e esquematiza sua rotina e sonha muito com os seus planos de vida.
Nome: Pedro da Silva.

Profissão: Bacharel e professor de física. Possui deficiência?

Daltonismo - deuteranomalia

- Gosta bastante de politica e de notícias a atualidade;

sta de tecnologia; dar sobre Hobbie em desmontar e montar aparelhos

Paixão por jogos:

Pensa muito sobre aborar na

Ama física e gostaria Não acredita em astrologia.

Domínio Tecnológico

Alto. Gosta muito de tecnologia e tem muito interesse em aprender. Usa pc desktop e possui celular. Usa diversas redes sociais. 


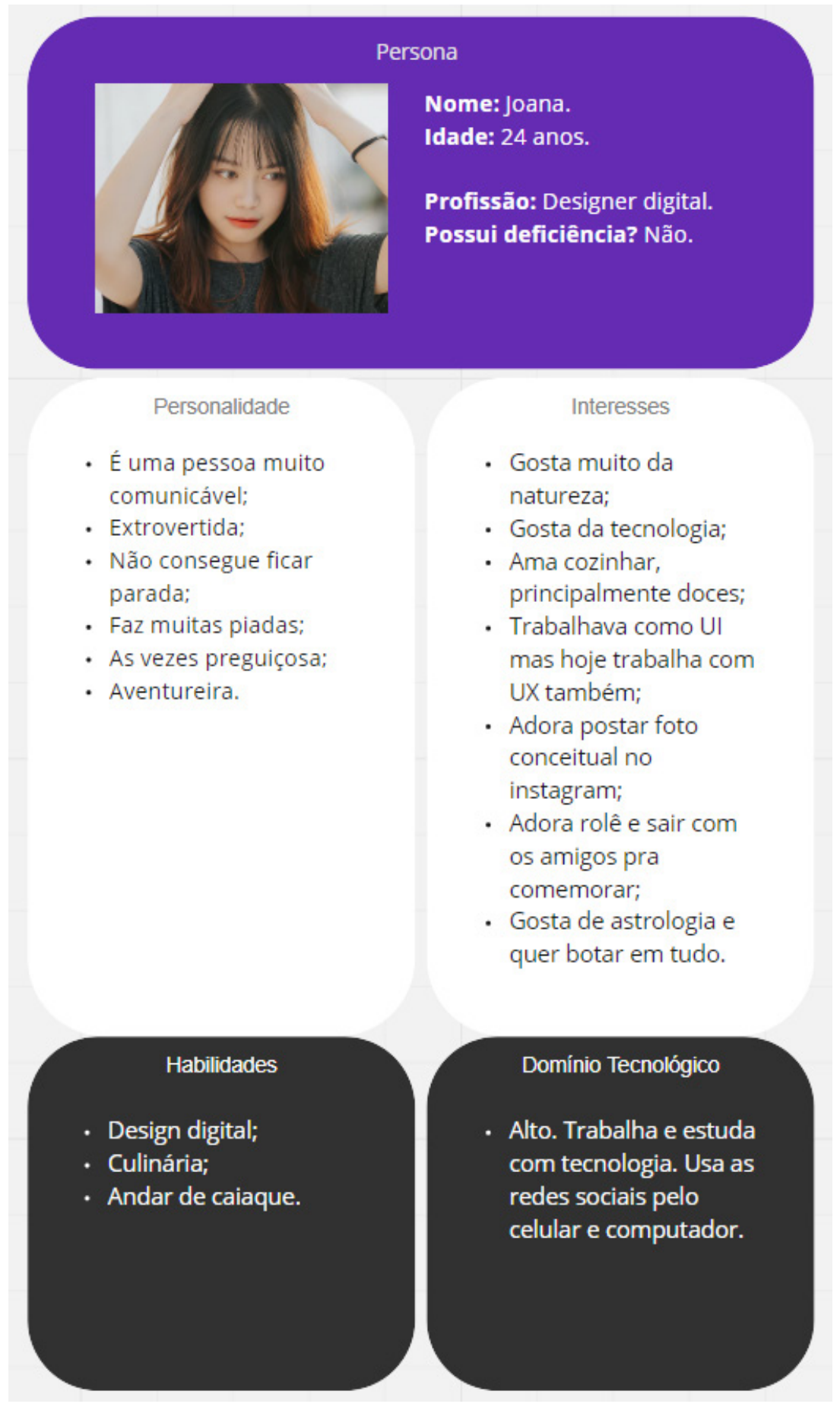

Figura 6 - Empatizar -

Imersão - Persona 2. Fonte:

Elaborado pela autora (2021).

É uma pessoa muito comunicável:

Extrovertida

Não consegue ficar parada;

Paz muitas piadas;

As vezes preguiçosa;

Aventureira.
Nome: Joana.

Profissão: Designer digital. Possui deficiência? Não.

- Gosta da tecnologia;

Ama cozinhar principalmente doces;

Principamente docesi mas hoje trabalha com

Adora postar foto conceitual no

Adora rolê e sair com os amigos pra comemorar;

Gosta de astrologia e quer botar em tudo. 


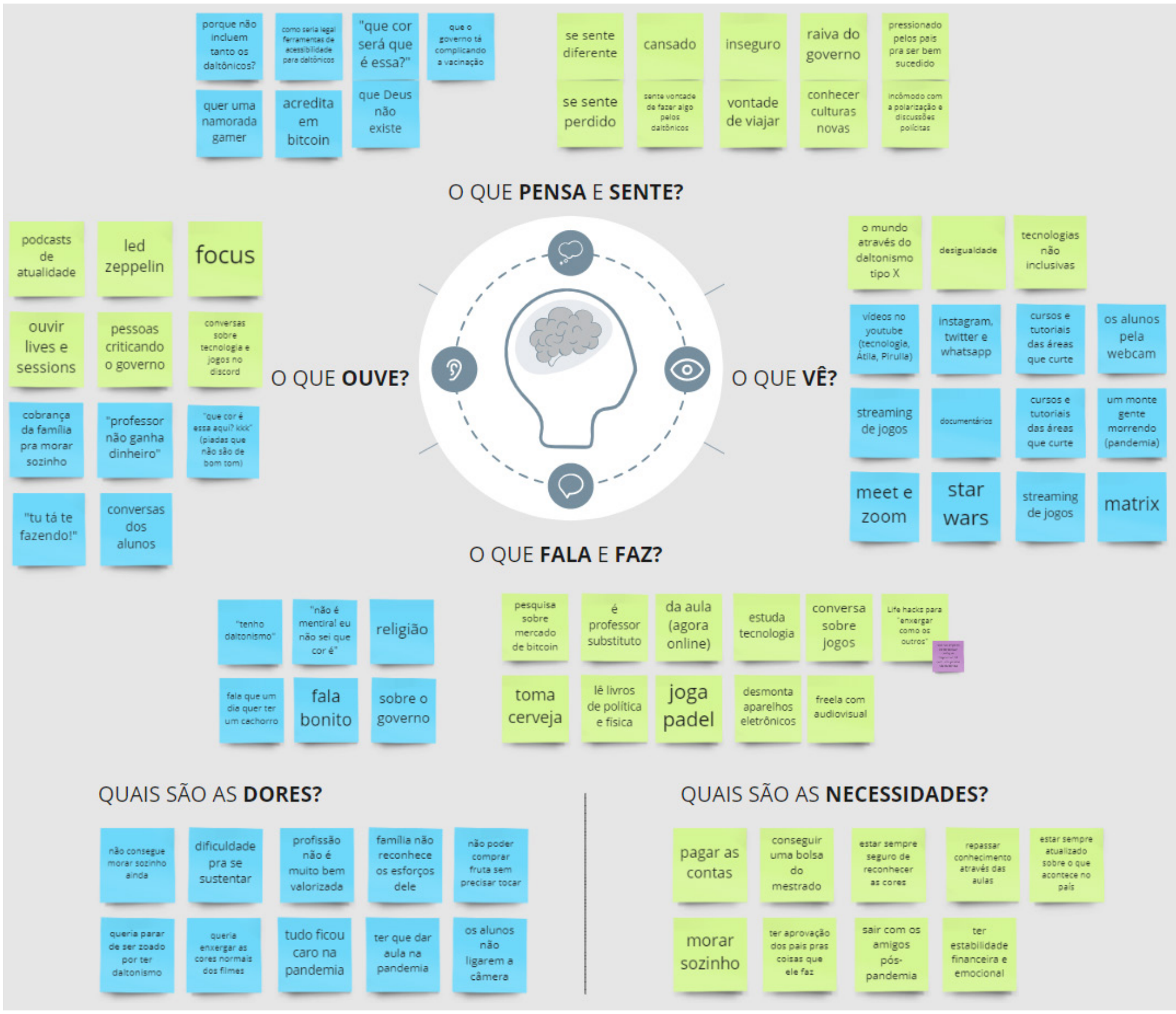

Figura 7 - Empatizar - Imersão - Mapa de empatia.

Fonte: Elaborado pela autora (2021).

relacionadas a sua incapacidade de reconhecer certas cores. Pedro fica muito em dúvida quando precisa reconhecer a cor verde e está sempre pensando sobre qual cor está atribuída a determinada imagem ou objeto. Ele se questiona do porquê não projetarem sinalizações em locais públicos ou sites $d a$ web mais inclusivos para pessoas daltônicas, sente cansaço e vontade de criar ações no que se diz respeito a visibilidade do 
daltonismo. Também se evidenciou que a persona fala incansavelmente que tem daltonismo, está sempre repetindo que não é mentira e que realmente não sabe a cor que é. Ele estuda tecnologia e utiliza de adaptações para enxergar como os outros. Suas dores são querer parar de ser "zoado"[11] por ter daltonismo e ter vontade de enxergar as cores normalmente. Suas necessidades são sempre estar seguro de reconhecer as cores e de repassar conhecimento através das suas aulas.

\subsection{ETAPA 02 - DEFINIR}

Durante os processos realizados na etapa anterior, Empatizar, percebeu-se que o daltonismo é uma deficiência que possui pouca visibilidade na sociedade e acaba não sendo discutida entre as pessoas, pois é diminuída a um distúrbio que afeta apenas a percepção visual. Com isto, a pessoa daltônica muitas vezes acaba sendo considerada desatenta ou inferiorizada porque não reconhece certas cores. O desenvolvimento de uma pessoa com o diagnóstico em meio a sociedade se torna complicado sem a compreensão de outras pessoas.

Nesta etapa da metodologia, Definir, se reconheceu que o problema está no repasse de conhecimento sobre o daltonismo, e que é extremamente necessário discutir acerca da deficiência. Se definiu que seria desenvolvido uma interface, com o objetivo de comunicar sobre o daltonismo, e de incentivar designers e desenvolvedores a projetarem interfaces mais inclusivas para o público.

\subsection{ETAPA 03 - IDEAÇÃO}

$\mathrm{Na}$ etapa Ideação, foram realizadas três rodadas da técnica Crazy 8's a fim de gerar insights, duas delas com outros designers previamente contextualizados sobre o projeto. A primeira rodada (figura 8) foi realizada com uma doutoranda em design e um mestrando em educação, a segunda rodada (figura 9) foi executada com um graduando em design, e a terceira (figura 10) foi desenvolvida individualmente.
[11] Gíria informal para o ato de tirar sarro de alguém. 


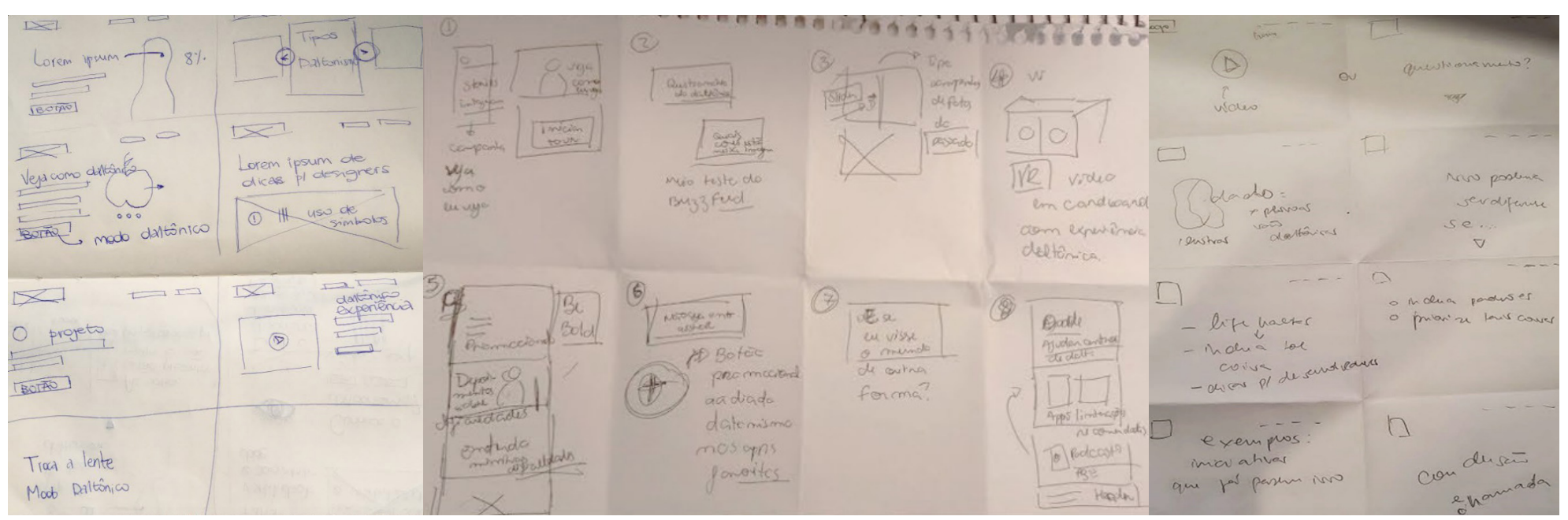

Figura 8 - Primeira rodada do Crazy 8's. Fonte: Elaborado pela autora (2021).

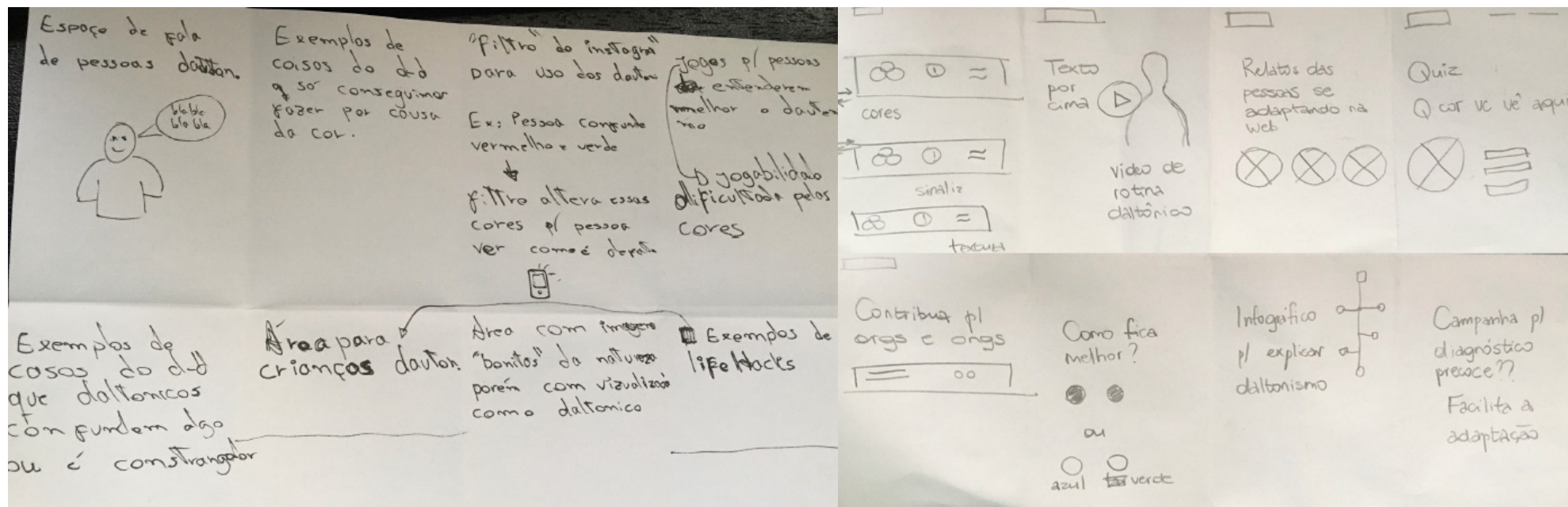

Figura 9 - Segunda rodada do Crazy 8's. Fonte: Elaborado pela autora (2021).

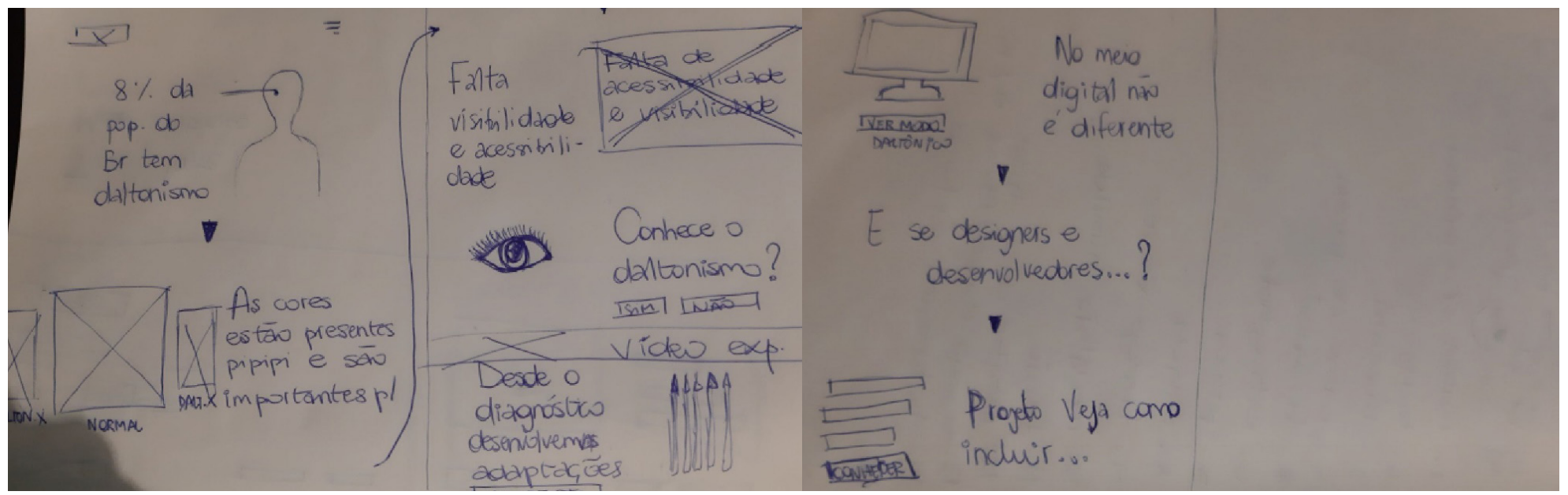

Figura 10 - Terceira rodada do Crazy 8's. Fonte: Elaborado pela autora (2021). 
O Crazy 8's possibilitou visualizar quais eram os tópicos mais relevantes para a abordagem e que tipo de ações conteriam as informações. Das três rodadas destacou-se as seguintes ideias: um botão para visualizar em "modo daltônico", onde seria possível observar uma simulação da plataforma na visão de um daltônico; a chamada "veja como eu vejo", convidando o usuário a assistir um vídeo de uma pessoa com daltonismo compartilhando suas experiências; um teste sobre daltonismo para reconhecer o nível de entendimento das pessoas sobre a deficiência; dicas para desenvolvedores e designers projetarem interfaces mais amigáveis para os daltônicos; área com imagens da natureza na visão de um daltônico, para mostrar visualmente como as coisas mais comuns podem ficar alteradas pela deficiência; exemplos das adaptações de pessoas com daltonismo, no intuito de mostrar suas realidades.

Ao finalizar-se a última rodada de Crazy 8's, reuniu-se todas as ideias e isto facilitou visualizar como seria o site, o tipo de abordagem que teria e quais as informações eram mais pertinentes para estarem sendo apresentadas.

\subsection{ETAPA 04 - PROTOTIPAR}

Após compreender o direcionamento da interface, foi construído um primeiro protótipo em wireframes de média resolução, na largura de 1440px. A estrutura do site foi estabelecida a partir de uma página principal, um menu, um quiz informativo e uma seção relacionada às adaptações comumente utilizadas por daltônicos. O conteúdo da plataforma foi distribuído da seguinte forma:

- Informações e dados sobre o daltonismo;

- Botão flutuante com a opção de visualizar o site em modo daltônico;

- Quiz para testar de maneira descontraída o nível de conhecimento dos usuários a respeito da deficiência;

- Vídeo com o dia a dia de um daltônico e as adaptações do público; 
- Questionamento a respeito de projetar interfaces amigáveis para o público;

- Dicas para auxiliar designers e desenvolvedores a compreenderem melhor as necessidades de pessoas com daltonismo ao fazerem o uso de interfaces digitais.

Após finalizada a estruturação, partiu-se para a representação visual da landing page. Para isto, foi desenvolvido um Moodboard ou Painel Semântico, um mural com referências visuais que tem como objetivo unir conceitos e definir uma proposta visual. Na figura 11 é apresentado as escolhas que foram feitas pela autora.
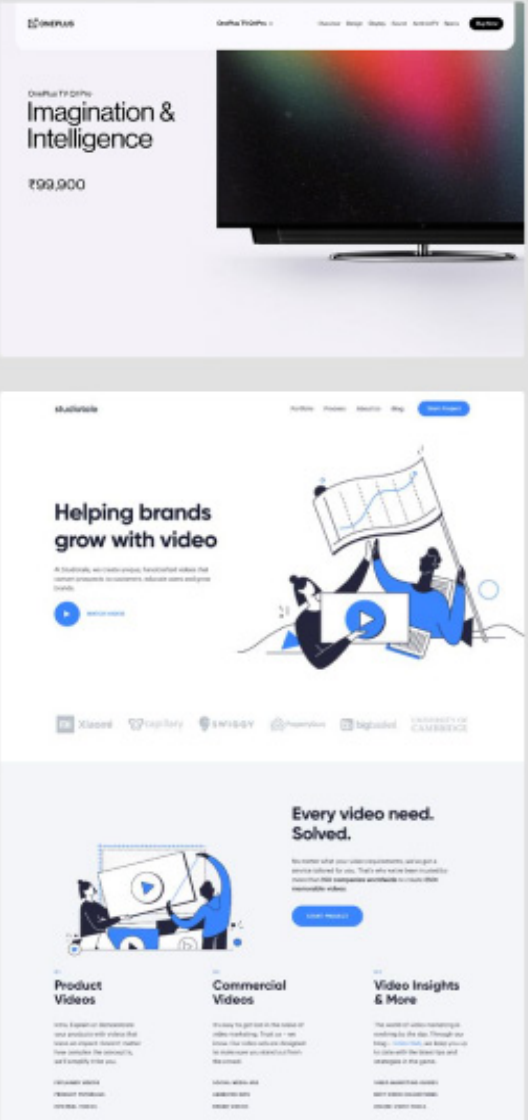

Our work

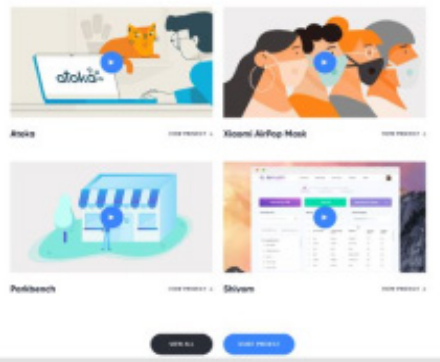

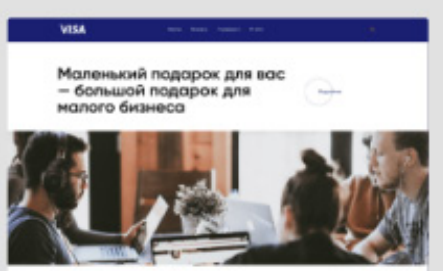
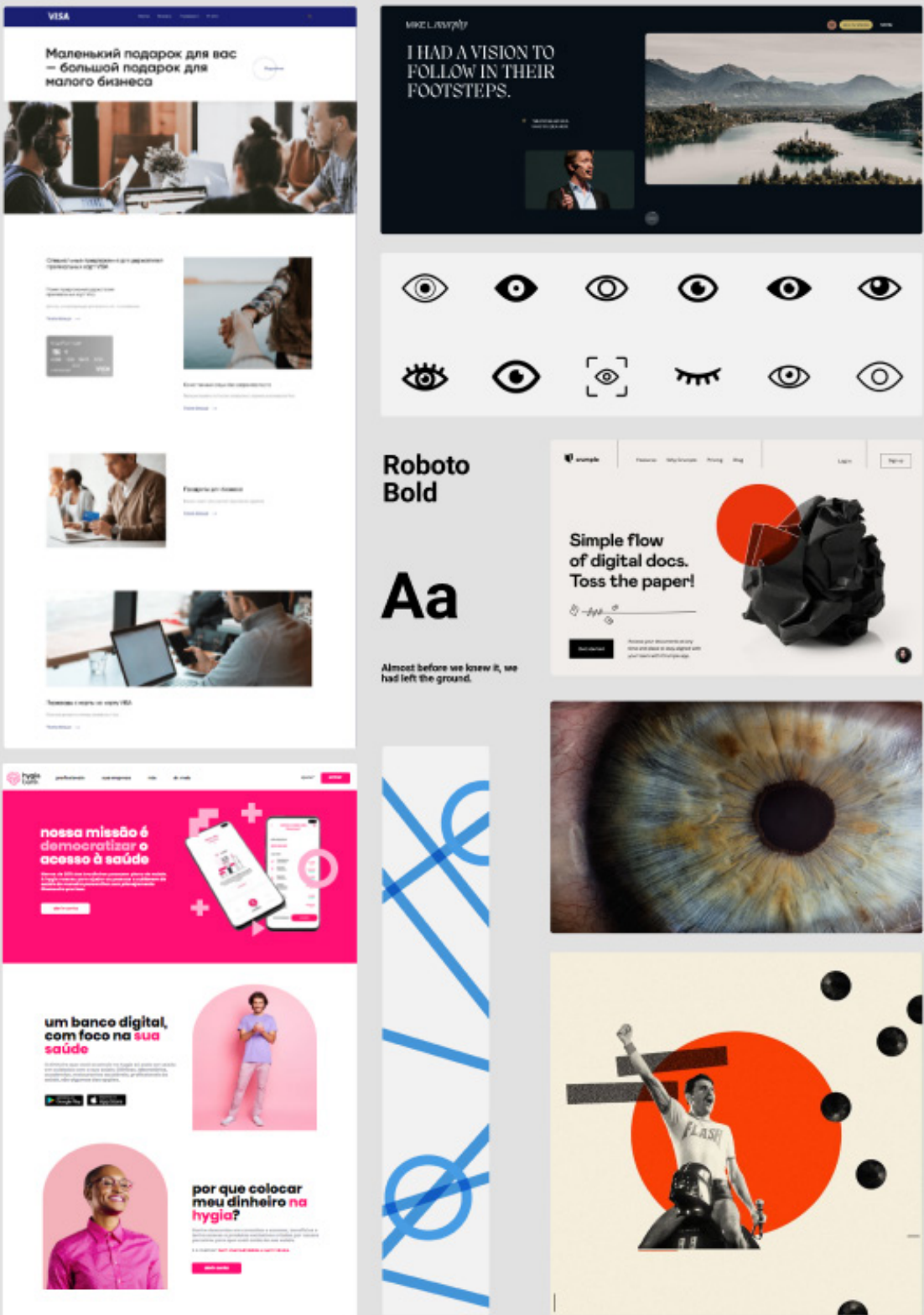

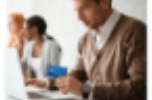

Roboto

Bold

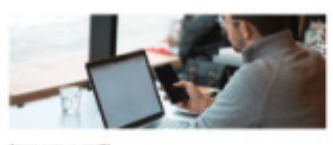

Aa

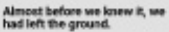
-
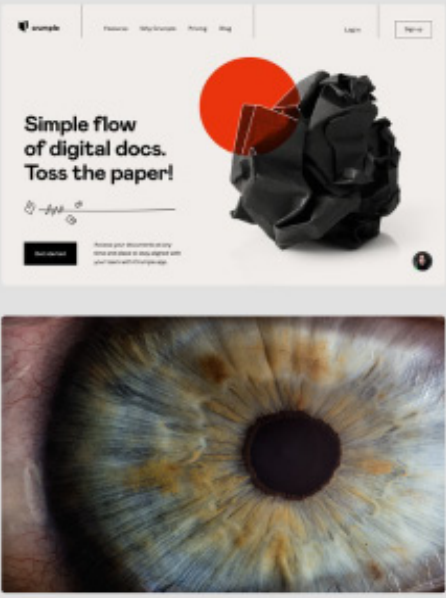
um baneo digita|
com foco na Iua
saúdo

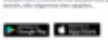

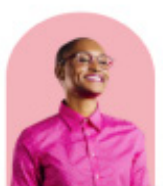

por que colocar

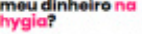

$=$

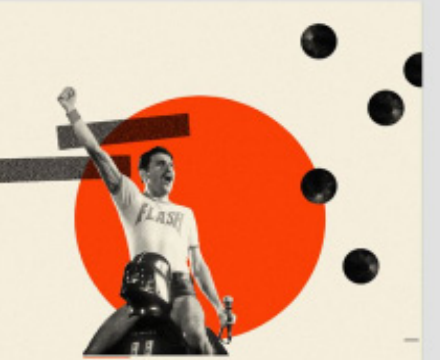


Uma vez que o azul é uma das cores que não possui grande alteração quando visualizada por um daltônico, de acordo com a pesquisa prévia, optou-se por utilizar uma paleta de cor em tons azuis, acompanhado de branco e algumas tonalidades de cinza. A fonte tipográfica utilizada na plataforma é Roboto Font Family, disponibilizada gratuitamente na plataforma Google Fonts ${ }^{[12]}$. Por se tratar de uma interface com uma única função, foi escolhido o grid $^{[13]}$ de 12 divisões e com uma única coluna no layout.

Ao finalizar a construção do site, se reconheceu a necessidade de inserir uma página externa com informações a respeito do projeto. Também houve a modificação da estrutura da plataforma (figura 12) para melhorar a navegação e aproveitar as informações, foi definido que a página Adaptações não seria mais uma página externa, e apresentaria todo o seu conteúdo na página principal.

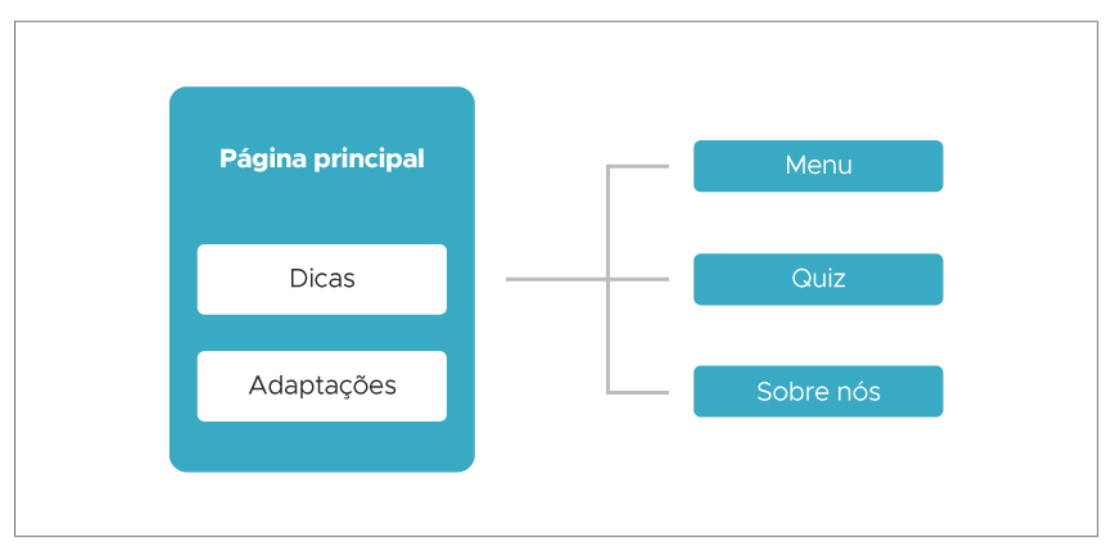

A página inicial do projeto (figura 13) inicia com o questionamento "Você sabia que o daltonismo é uma deficiência visual que atinge aproximadamente 300 milhões de pessoas no mundo?", e possui um indicativo para a pessoa "rolar para baixo" para que o usuário possa visualizar os demais conteúdos. Ao topo da página, há uma barra de carregamento, no canto superior direito encontra-se o menu e na parte inferior deste mesmo lado está um botão flutuante para visualizar a página em modo daltônico.
[12] Disponível em: <fonts. google.com $>$ Acesso em 21/07/2021.

[13] Divisão da tela por colunas, com o objetivo de distribuir o conteúdo de forma proporcional e harmônica.

Figura 12 - Modificação da estrutura da plataforma. Fonte: Elaborado pela autora (2021). 


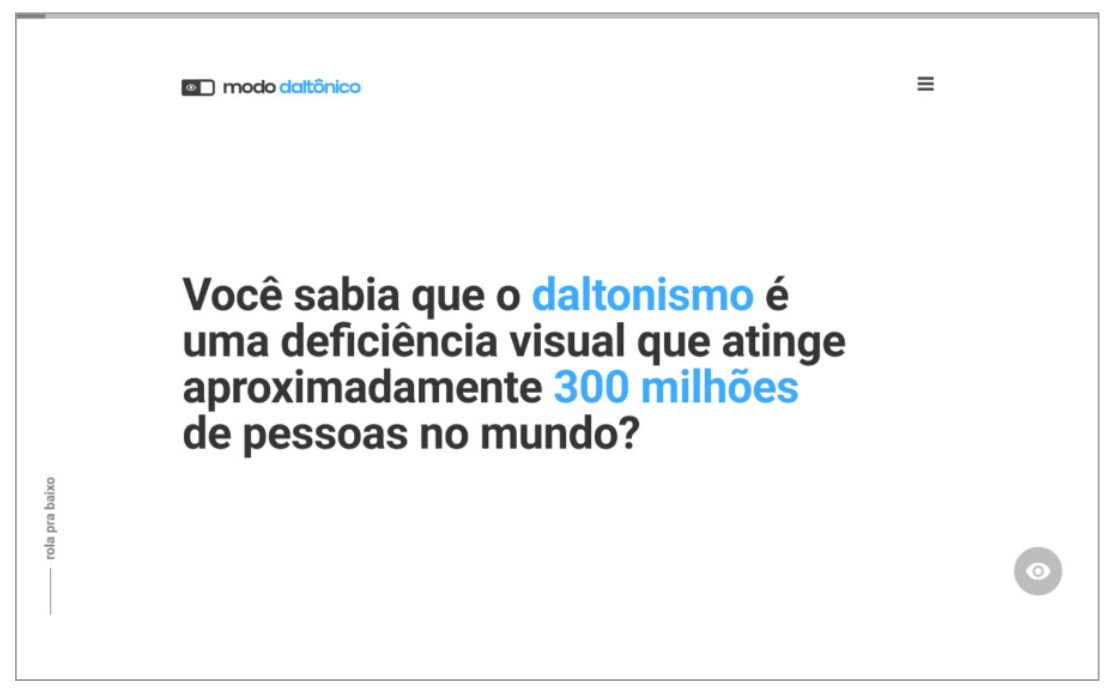

Figura 13 - Início da página principal do protótipo. Fonte: Elaborado pela autora (2021).

Quando o usuário passa o mouse por cima do botão de modo daltônico e não o ativa (figura 14), uma mensagem explicativa aparece e o sugere para que experimente o modo. No momento que é clicado e ativado o modo a tela muda para a visão de um daltônico tipo deuteranomalia.

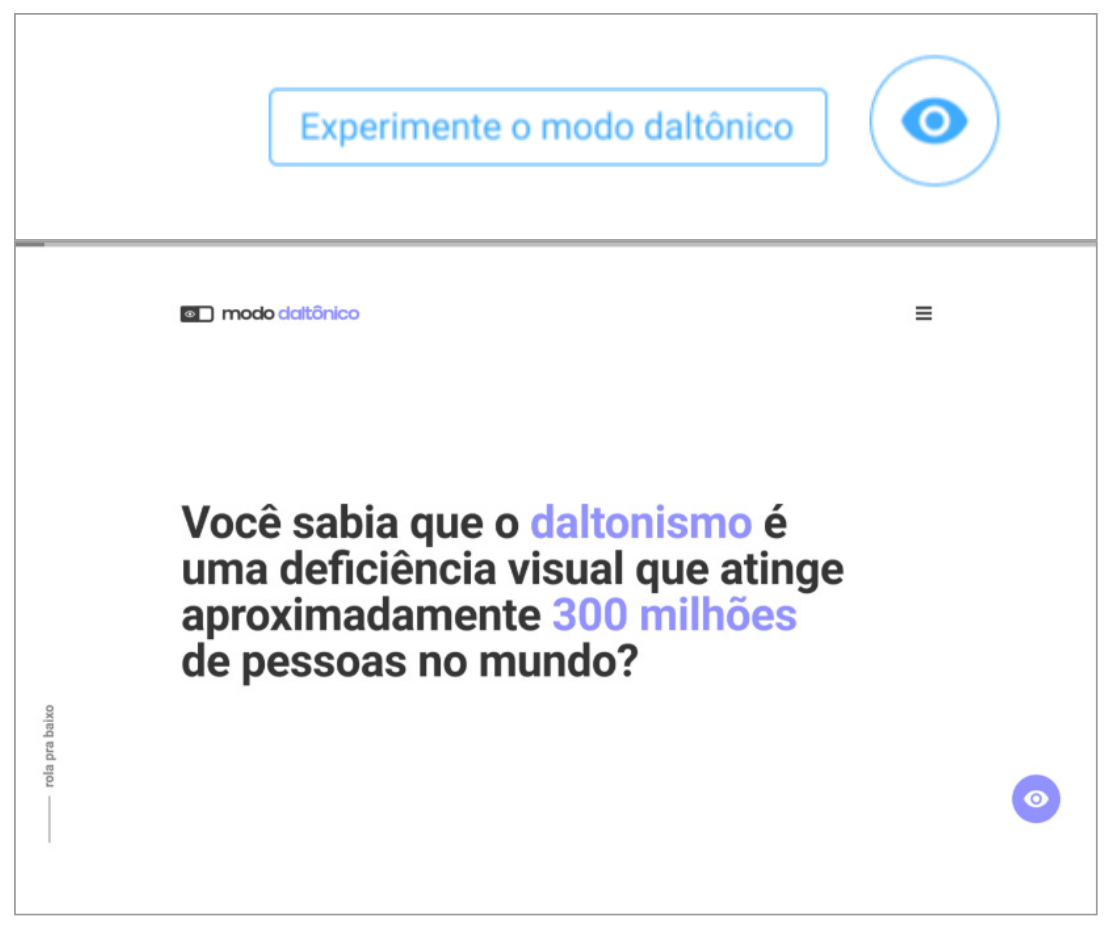

Figura 14 - Mouse em cima do botão e plataforma no modo daltônico. Fonte: Elaborado pela autora (2021). 
O menu é fixo no canto superior direito e pode ser acionado com um clique (figura 15). Nele é possível chegar nas seções "Home", "Quiz", "Adaptações", “Dicas" e "Sobre nós" a qualquer instante.

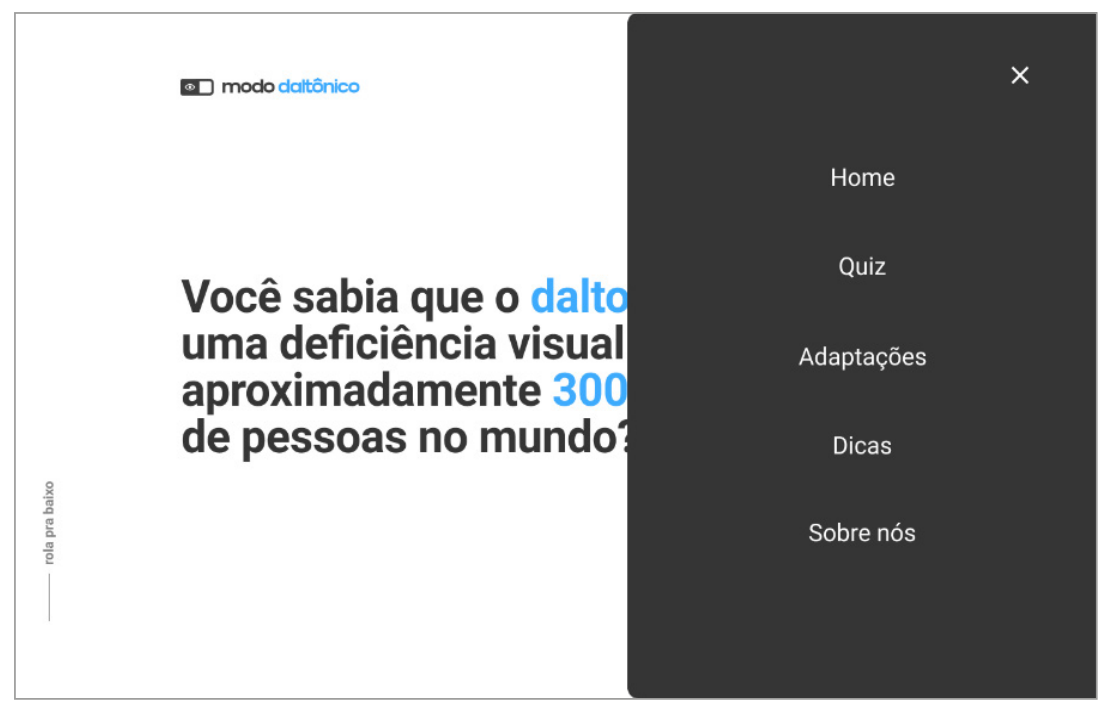

Ainda na página inicial, em exibição normal, é apresentado a frase "Um mundo de cores" (figura 16) e um texto de apoio falando a respeito da importância das cores e como elas indiretamente nos afetam. Nessa tela há uma imagem da natureza e um carrossel com botões, para visualizar nos diferentes tipos de daltonismo.

Ao rolar para baixo na página, uma tela com o questionamento "O quanto você entende sobre daltonismo?" surge e convida o usuário para participar de um quiz (figura 17) e ver o quanto o sabe sobre o assunto.

Se o usuário optar por participar do quiz, o site redireciona para uma página externa e uma série de perguntas são aplicadas (figura 18).

Depois que finalizado o quiz a plataforma redireciona o usuário para a página inicial e aborda a "Pouca visibilidade e acessibilidade" que os daltônicos sofrem. Após isto, apresenta um vídeo de uma pessoa convivendo com o daltonismo (figura 19).
Figura 15 - Menu. Fonte: Elaborado pela autora (2021). 


\section{Um}

\section{mundo de cores}

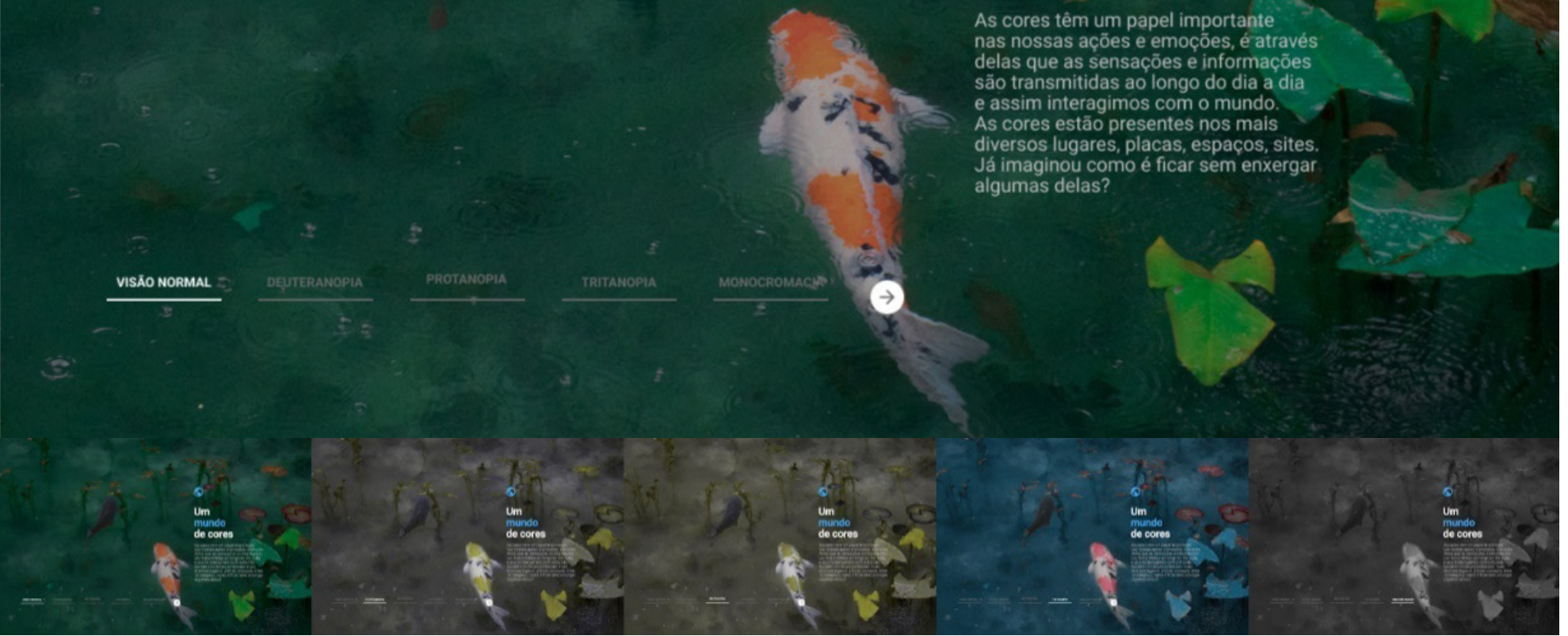

Figura 16 - Carrossel dos diferentes tipos de daltonismo.

Fonte: Elaborado pela autora (2021).

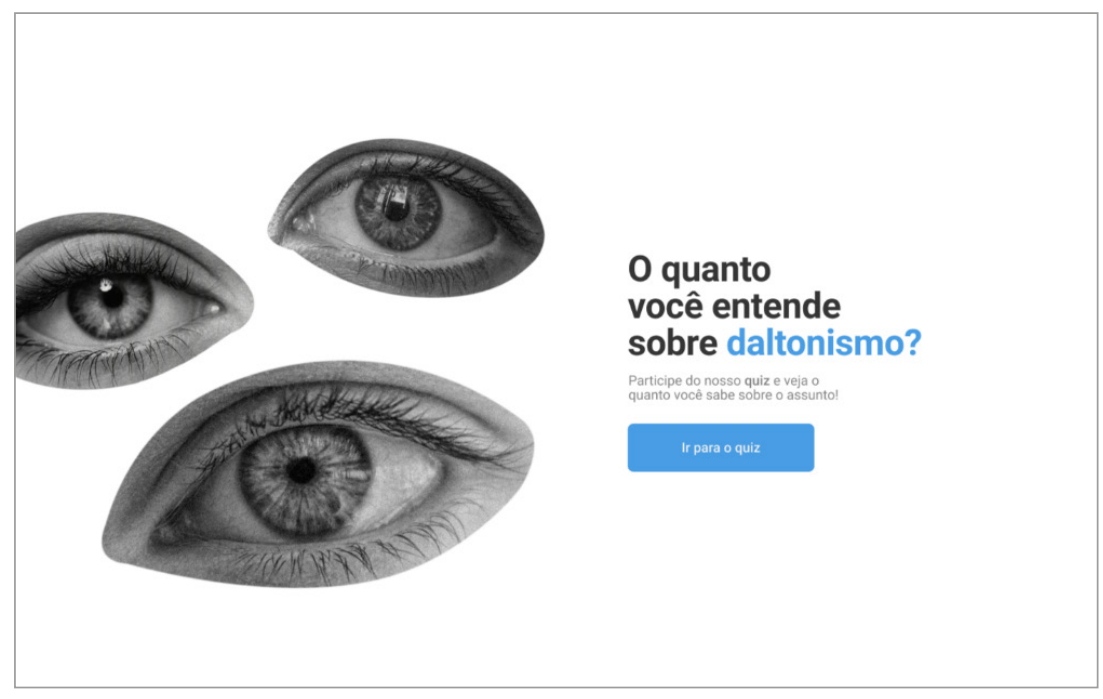

Figura 17 - Chamada para

o quiz. Fonte: Elaborado

pela autora (2021). 
O daltonismo é uma...

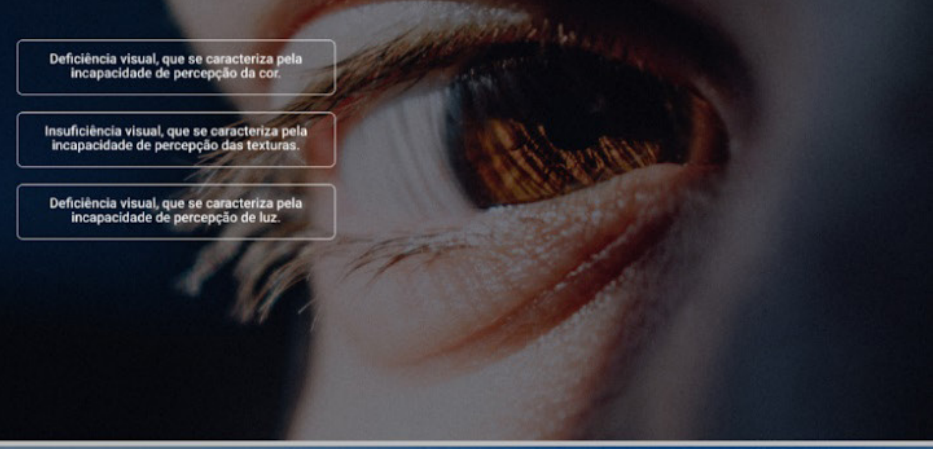

๑ modo dallínico

Ocorre com mais

frequência em...

\section{Existe tratamento} para daltônicos?

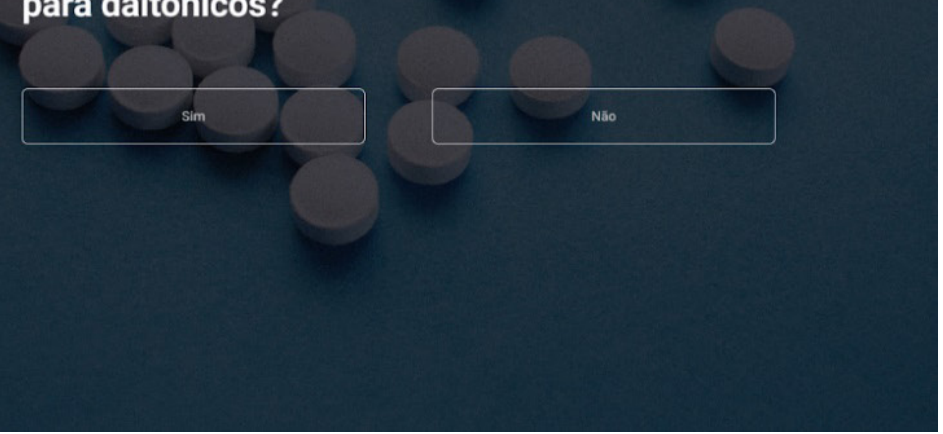




\section{Pouca} visibilidade e acessibilidade

O daltonismo nắo possui tratamento ou cura, com isso, os daltônicos necessitam se adaptar individualmente para suprir suas necessidlades. Além do esforco de sempre precisar explicar para cutras pessoas que eles nåo visualizam determinadas cores, a falta de acessibilidade resulta em um esforco duplo do usuário para realizar tarefas simples, como acessar uma página da web.

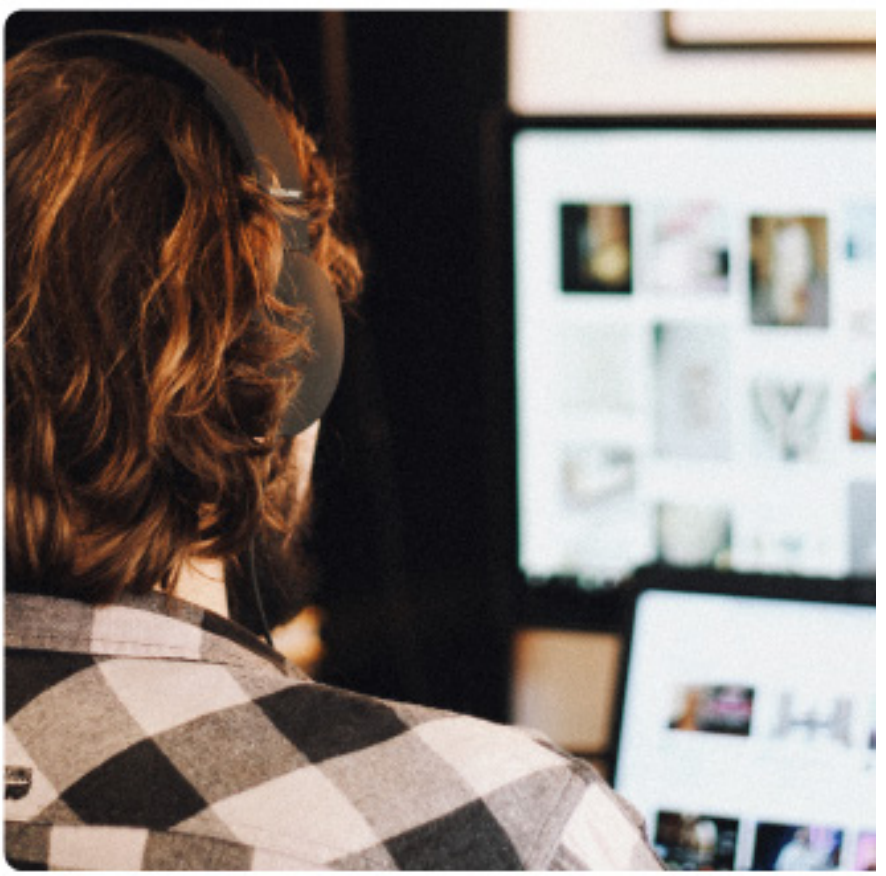

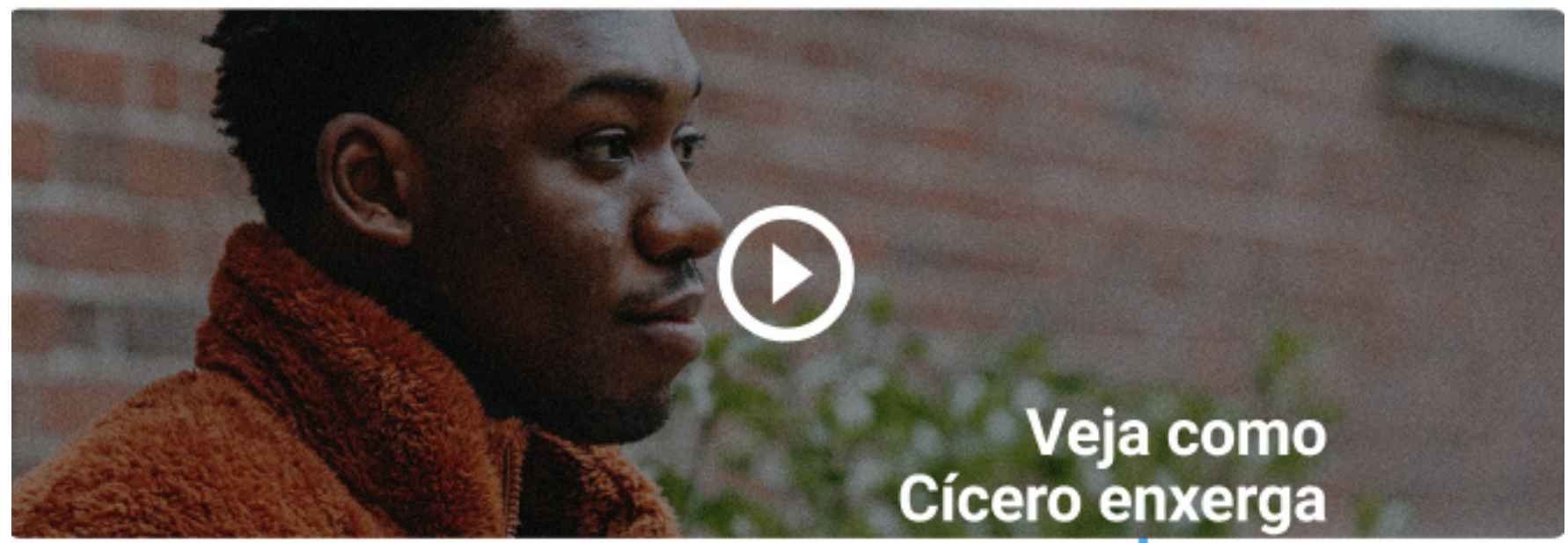

o mundo com daltonismo

Figura 19 - Texto e vídeo sobre pouca visibilidade e acessibilidade. Fonte: Elaborado pela autora (2021). 
Ao clicar no vídeo, a ideia é que o usuário seja direcionado a um vídeo explicativo sobre a rotina de uma pessoa daltônica, mostrando algumas dificuldades e barreiras enfrentadas no dia a dia.

Em seguida é apresentado o título “Desde o diagnóstico os daltônicos desenvolvem suas próprias adaptações" com o texto de apoio abordando sobre as dificuldades que pessoas com daltonismo enfrentam. Embaixo contém quatro cartões com quatro adaptações (figura 20), quando clicados é ativada uma imagem e um texto diferente.

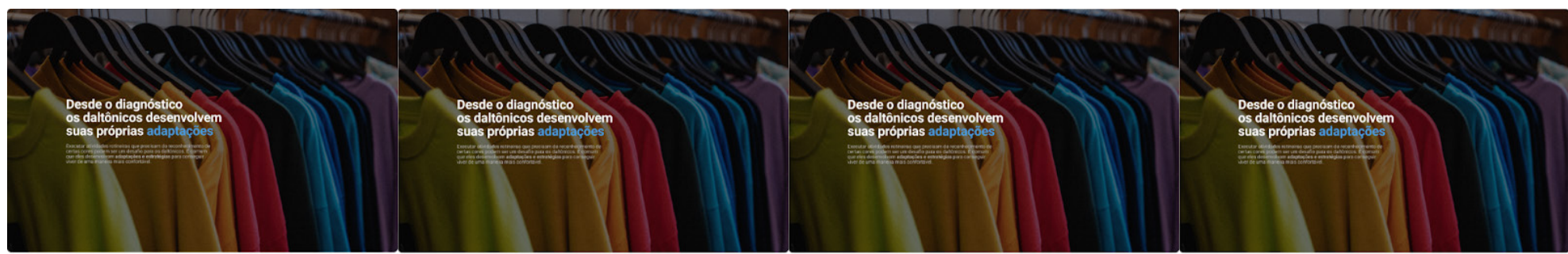

Ir ao
supermercado
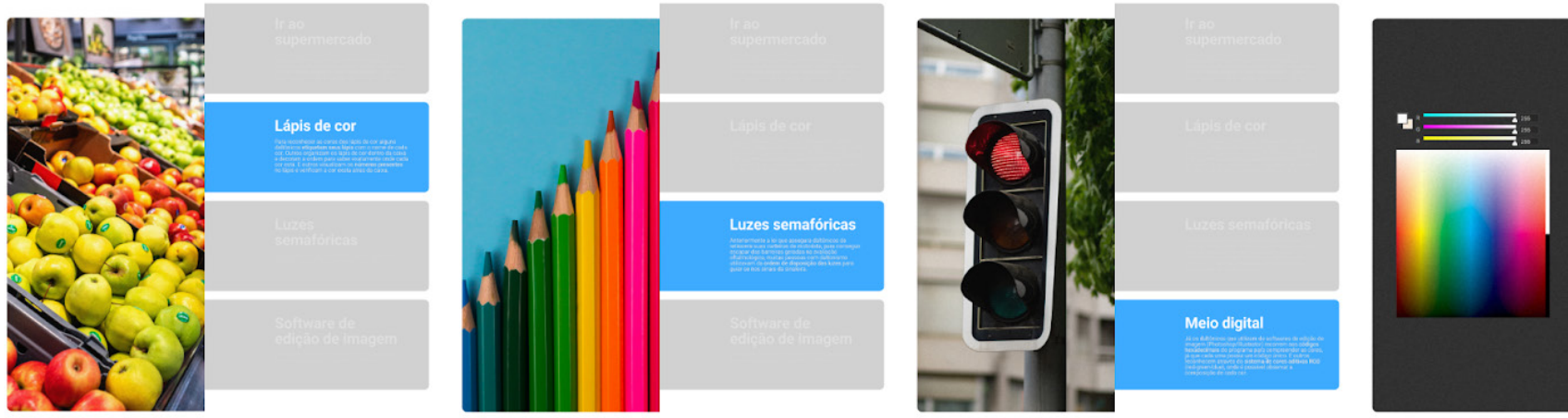

Figura 20 - Adaptações. Fonte: Elaborado pela autora (2021).

Após informar e abordar acerca do daltonismo, é feito o questionamento por meio da frase: "Designers e desenvolvedores, será que estamos projetando interfaces amigáveis para estas pessoas?", em seguida, "Que tal proporcionarmos uma experiência mais inclusiva na web?", e após isso é oferecida a resolução: "A gente quer mostrar para você algumas dicas sobre como incluir os daltônicos em meio digital" (figura 21). 


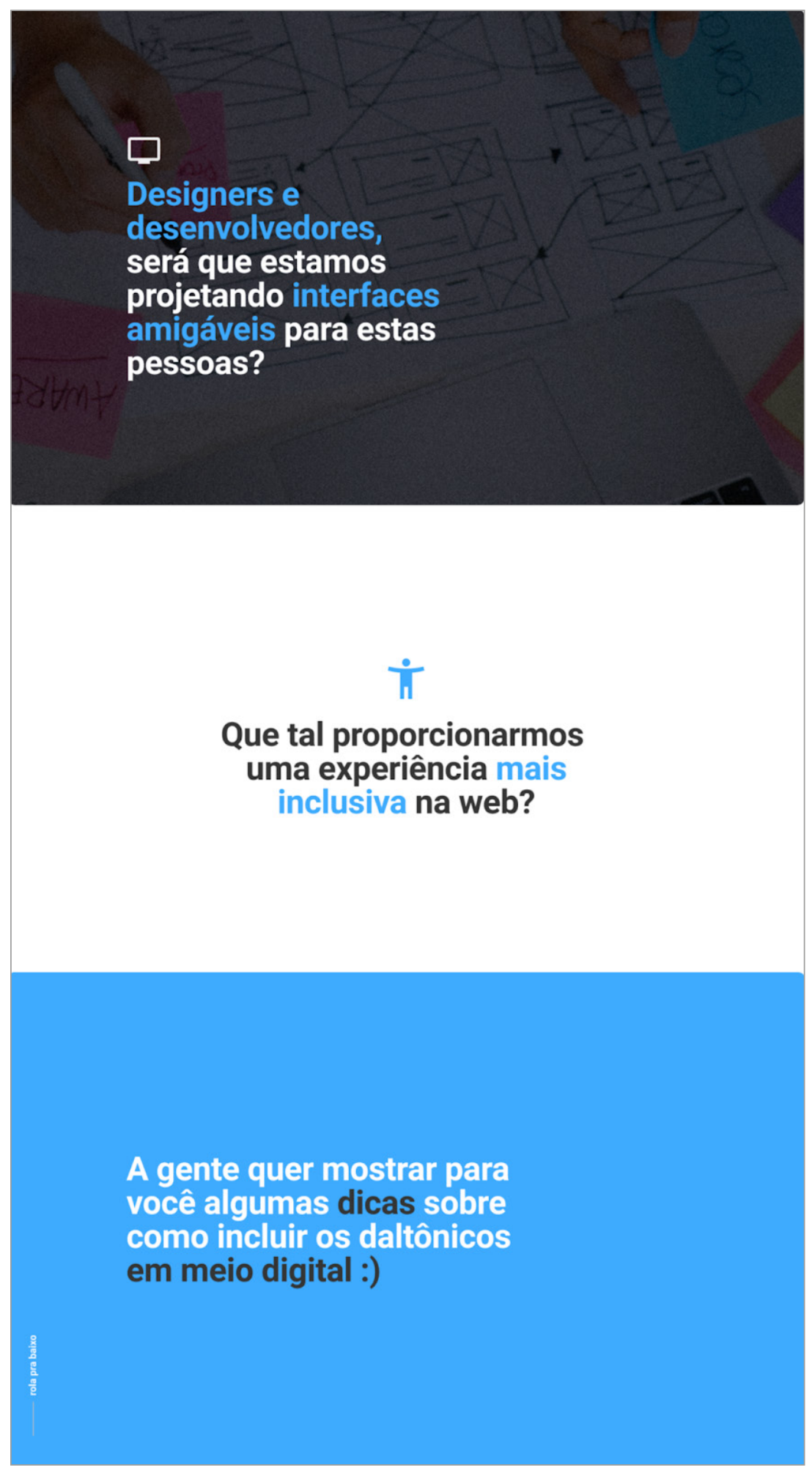

Figura 21 - Questionamento e resolução. Fonte: Elaborado pela autora (2021).

A gente quer mostrar para você algumas dicas sobre como incluir os daltônicos em meio digital :) 
As dicas (figura 22) são apresentadas em uma ordem indicada por números, e é possível visualizar as demais informações clicando no botão no canto inferior direito, que irá deslizar para o lado.

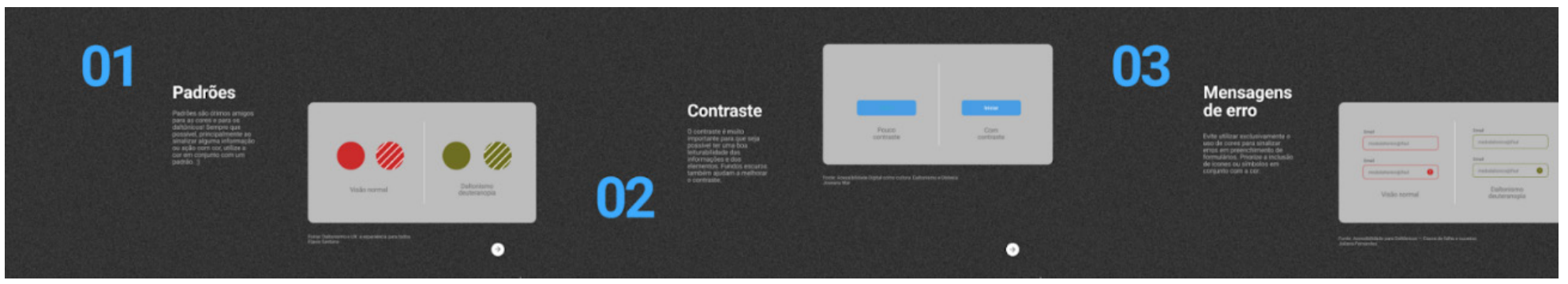

Figura 22 - Dicas. Fonte: Elaborado pela autora (2021).

Em seguida são sugeridas algumas leituras (figura 23) de matérias relacionadas ao tema, através de links. Após, há uma chamada para receber mais informações sobre o tema (figura 24), no qual o usuário poderá preencher as caixas de texto com o nome e e-mail caso deseje se cadastrar.

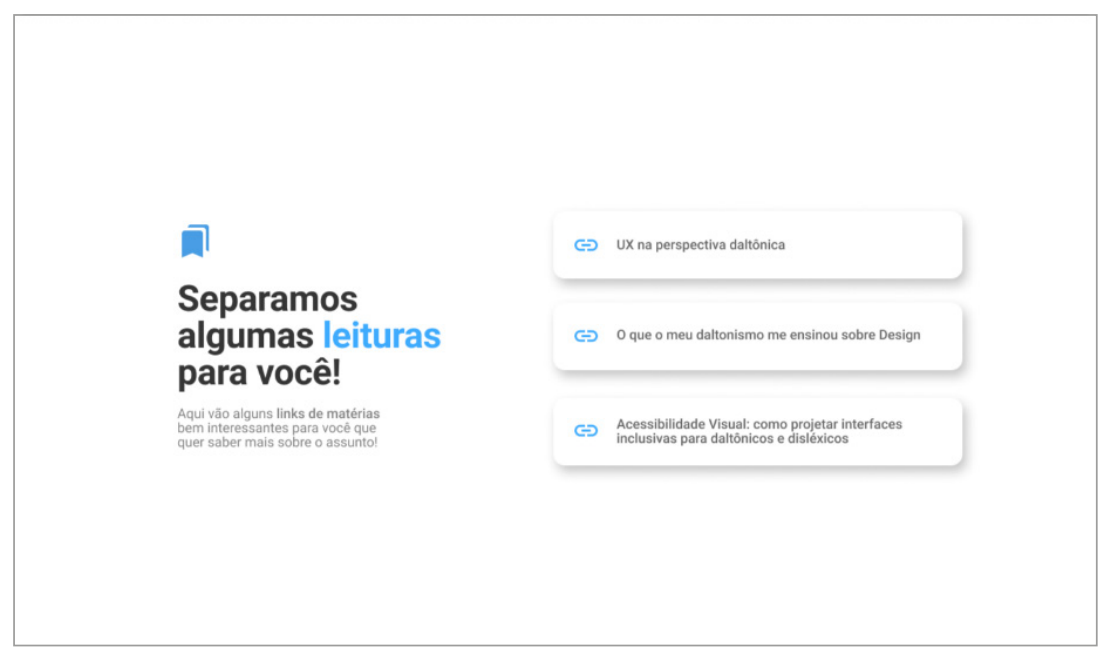

Figura 23 - Leituras

recomendadas. Fonte: Elaborado pela autora (2021). 
Quer receber

mais informações

sobre esse tema?

Te cadastra na nossalista de e.malls.
promelemos mandar so colisas legalis insira o seu nome aqu

insiraoseuemailaqui@

Receber
Figura 24 - Recebimento de conteúdo por e-mail. Fonte: Elaborado pela autora (2021).

Por fim, encontra-se o rodapé da página inicial (figura 25), contendo informações sobre quem criou, e botões "Sobre nós" e "Siga a gente". Quando clicado em "Sobre nós" o usuário é redirecionado para uma página externa que contém informações mais específicas sobre o projeto e os objetivos de quem criou a página (figura 26).

๑๐ modo daltônico

Figura 25 - Rodapé. Fonte: Elaborado pela autora (2021). 


\section{Olá!}

O protótipo finalizado está disponível para acessar neste link: https://bityli.com/3fY1।

Durante a finalização da interface, pensou-se no nome e na marca que a plataforma teria. O nome escolhido foi Modo Daltônico, inspirado na funcionalidade do site que possibilita visualizar a interface em uma versão de simulação do daltonismo e também no objetivo do projeto de fazer as pessoas experenciarem a vivência com a deficiência e empatizarem com os deficientes.

\subsection{ETAPA 05 - TESTAR}

Após concluído o desenvolvimento do protótipo, este foi validado com três usuários, de forma remota. O acesso ao protótipo na plataforma Figma foi enviado para os participantes via Whatsapp e solicitado para que respondessem, pelo pró- 
prio aplicativo, a um roteiro de perguntas (figura 27), sobre a relevância do tema e a sua experiência prévia em relação ao uso da plataforma. Dos três participantes, dois são da área da tecnologia, um designer e um desenvolvedor, e entre os três um deles é daltônico.

\section{ROTEIRO}

- Já conhecia sobre o daltonismo?

- Conhecia alguma plataforma assim?

- Se for da área de tecnologia, já pensou em daltônicos quando projetava?

- O conteúdo é relevante?

- Em uma escala de 1 a $10 . .$.

A navegação está:

Pertinência do conteúdo:

Layout:

Hierarquização das informações:

Clareza das informações:

Todos os 3 participantes já conheciam o daltonismo, especialmente um dos participantes que é daltônico. Dos 3 participantes 2 não conheciam uma plataforma semelhante e 1 relatou conhecer uma plataforma que possuísse a visualização do daltonismo, mas não uma com intuito de abordar o 
problema e informar sobre. Os 2 participantes que atuam na área da tecnologia já pensaram neste público ao projetar alguma interface. Os 3 participantes acham o conteúdo relevante, e um deles ressalta que a plataforma é informativa, expõe a problemática e demonstra resoluções. Tais dados estão sumarizados na Figura 28:

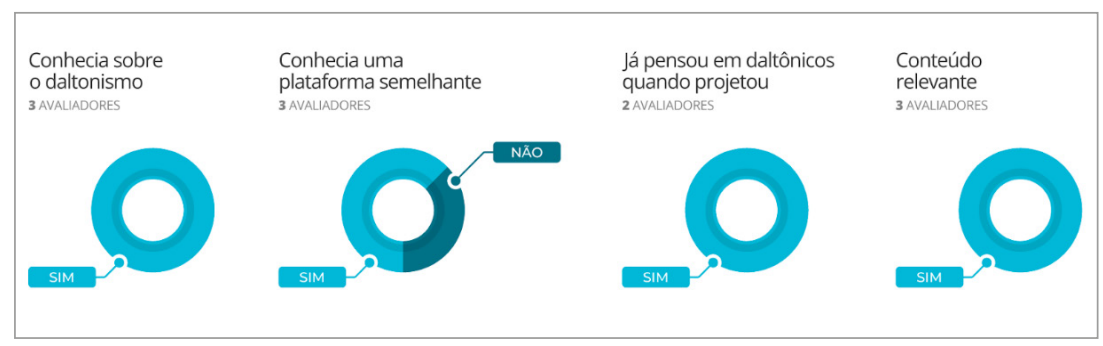

Figura 28 - Experiência prévia. Fonte: Elaborado pela autora (2021).

Sobre a plataforma desenvolvida, os participantes atribuíram notas de 0 a 10 para critérios como navegação, layout, pertinência do conteúdo, hierarquização das informações e clareza das informações. A média das notas atribuídas pode ser visualizada no gráfico a seguir (figura 29):

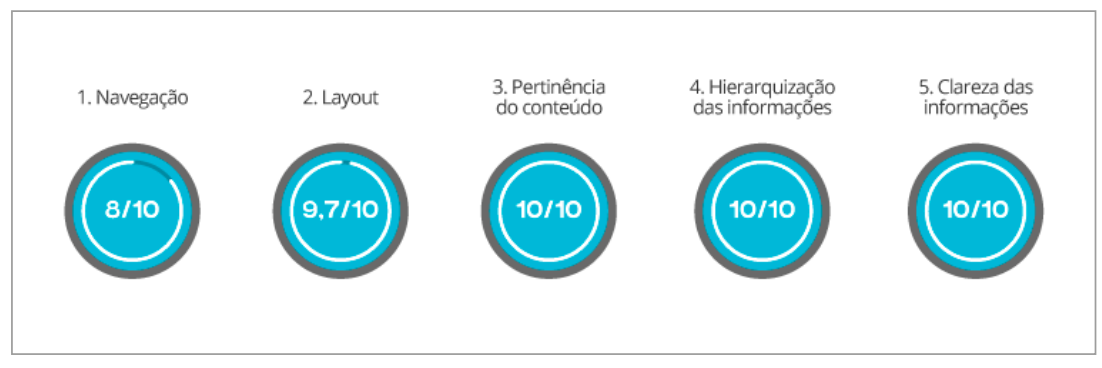

Figura 29 - Média das avaliações da plataforma.

Fonte: Elaborado pela autora (2021). 
A média de avaliação dos participantes para a navegação foi de 8/10, layout 9,7/10, pertinência do conteúdo 10/10, hierarquização das informações 10/10 e clareza das informações 10/10. Os 3 participantes fizeram considerações a respeito de suas avaliações para a navegação. Ambos justificaram que a navegação do protótipo está um pouco confusa, limitada ou trancada, e utilizam como exemplo as páginas das variáveis do daltonismo ou adaptações, onde após finalizar a visualização destas o site volta para o topo da página inicial. Posteriormente a avaliação dos usuários, foi modificado o fluxo do protótipo, onde se tentou chegar em um nível de visualização mais próximo do desejado.

\section{CONSIDERAÇÕES FINAIS}

Ao longo da etapa da pesquisa e do desenvolvimento do trabalho a falta de informação a respeito do daltonismo, e com isso, a importância de comunicar-se, informarmos e darmos visibilidade à deficiência, com o objetivo de oferecermos a estas pessoas experiências mais igualitárias, sejam estas em ambientes públicos ou na web.

A metodologia utilizada foi fundamental no decorrer da pesquisa. Por possuir a abordagem com foco na compreensão do problema, e nas dificuldades que o público-alvo enfrenta, desde o começo do desenvolvimento do projeto a metodologia auxiliou determinar quais caminhos deveriam ser tomados para desenvolver uma solução mais relevante. A persona Pedro e o mapa de empatia foram essenciais para empatizar com os daltônicos e conseguir visualizar o contexto em que eles estão inseridos, propiciando uma melhor comunicação para expor as suas dores e dificuldades ao público designer e desenvolvedor na plataforma. Diante disso, a técnica pode ser de extrema valia para projetos de desenvolvimento de produtos que visem a inclusão de grupos que necessitam de um olhar mais cuidadoso.

Perante os resultados apresentados na etapa Testar, é possível afirmar que os objetivos do projeto foram alcançados, pois as necessidades e barreiras que o público enfrenta 
foram reconhecidas e a plataforma cumpre com êxito a proposta de comunicar sobre o daltonismo, informando sobre as suas dificuldades e convidando outras pessoas a refletirem. Apesar da dificuldade de entrar em contato com diferentes pessoas para realizar a validação do protótipo, por conta da pandemia da COVID-19 ${ }^{[14]}$, o retorno dos participantes foi positivo, em suma todos consideram importante abordar sobre a temática, acham pertinente a forma como isto foi abordado e tiveram uma experiência satisfatória ao utilizar a landing page.

Depois da etapa de validação percebeu-se que, para melhorias na navegação do protótipo, faz-se necessário que este seja desenvolvido em conjunto de um desenvolvedor, a fim de programar e implementar as funções e ações desenhadas ao longo do desenvolvimento do projeto, proporcionando uma maior fluidez à experiência do usuário. Também seria indicado realizar determinadas modificações em sua estrutura, tais como: adicionar micro interação ao botão do modo daltônico, a fim de chamar a atenção dos usuários; aumentar a entrelinha dos parágrafos, melhorando a sua leiturabilidade; adicionar um botão para voltar nas dicas para designers e desenvolvedores; padronizar os títulos das seções como "sobre a gente" e "siga a gente".

Além disso, é importante salientar que, em muitos momentos, houve dificuldade de encontrar informações sobre a deficiência, devido a falta de dados específicos e estatísticas a respeito deste grupo. Assim, faz-se necessário uma maior disponibilização de materiais e conteúdos sobre o daltonismo, tanto quanto dados atualizados, que auxiliem no entendimento sobre a deficiência e facilitem o processo de empatizar e compreender este público. Contudo, a partir do desenvolvimento deste trabalho, percebeu-se que a tecnologia aliada ao design de interfaces tem um grande potencial de provocar a reflexão e auxiliar as pessoas a compreenderem diferentes realidades. Sendo assim, espera-se que este trabalho ajude a fomentar a discussão sobre o daltonismo e que incentive demais pessoas a pesquisarem e informarem-se sobre $o$ assunto.
[14] A preocupação em desconhecer a proporção que esse momento tomaria em muitos momentos também desmotivou e atrasou o andamento do trabalho. Ao mesmo tempo, este período significou um momento de reflexão e cuidado com o próximo, gerando mais empatia para compreender o que seria o público deste projeto. 


\section{REFERÊNCIAS BIBLIOGRÁFICAS}

AMPHILÓQUIO, W.; SOBRAL, J. E. C. Design e sociedade: uma reflexão sobre acessibilidade, interação e inclusão.

Human Factors in Design - Edição Especial - ISA

2017, Florianópolis, v. 7, n. 13, p. p. 165-176, mai 2018.

AWARENESS, C. B. Colour Blindness. Colour

Blindness Awareness, 2021. Disponível em: <https:// bit.ly/33GRFfg>. Acesso em: 21 maio 2021.

BRUNI, L. F.; CRUZ, A. A. V. Sentido cromático: tipos de defeitos e testes de avaliação clínica. Arq. Bras. Oftalmol, São Paulo, v. 69, n. 5, p. 766-775, Out 2006.

BRUNI, L. F.; CRUZ, A. A. V. E. Sentido cromático: tipos de defeitos e testes de avaliação clínica. Arquivos Brasileiros de Oftalmologia, São Paulo, v. 69, n. 5, p. 766-775, Out 2006.

ECHOS, E. D. T. Mini Toolkit de Design

Thinking. São Paulo: [s.n.], 2015.

FARINA, M.; RODRIGUES, M. C. P.; FILHO, H. T.

B. Psicodinâmica das cores em comunicação.

5a. ed. São Paulo: Editora Blucher, 2006.

GOMES, D.; QUARESMA, M. O contexto do design inclusivo em projetos de produto: Ensino, prática e aceitação. Blucher Proceedings, Belo Horizonte, Dez 2016. 3143-3155.

GORDON, N. Colour blindness. Public Health, v. 112, n. $2^{\text {a }}$, p. 81-84, Mar 1998.

IIDA, I. Ergonomia - Projeto e produção. São

Paulo: Editora Blucher , 2005. 630

JOOST, G.; BIELING, T. Design contra a Normalidade.

Traduzido do inglês por Paulo Ortega. Vírus

7, São Carlos, 2012. Disponível em: <https://

bit.ly/3qcbrH5>. Acesso em: 12 Mai 2021. 
LIMA, A. C. D. Brinquedo e jogo interativo, com foco no incentivo a aprendizagem do sistema de identificação das cores para daltônicos - Color Add. Universidade Federal da Paraíba - Curso de Design. Paraíba, p. 103. 2015.

MAIA, A. F. D. V. M. D. Representação Gráfica de Mapas para Daltônicos: Um Estudo de Caso dos Mapas da Rede Integrada de Transporte de Curitiba. Universidade Federal do Paraná - Programa de PósGraduação em Design. Curitiba, p. 193. 2013.

MAIA, A.; SPINILLO, C. G. Como os daltônicos percebem as representações gráficas de mapas: um estudo de caso dos códigos de cores utilizados nos diagramas e estação-tubo do transporte público de Curitiba. Design e Tecnologia, Porto Alegre, v. 3, n. 5, p. 15-23, Ago 2013.

MELO, A. M.; BARANAUSKAS, M. C. C. Design Inclusivo de Sistemas de Informação na Web. Unicamp. Campinas. 2005.

MELO, D. G.; GALON, J. E. V.; FONTANELLA, B. J. B. Os "daltônicos" e suas dificuldades: condição negligenciada no Brasil? Physis, Rio de Janeiro, v. 24, n. 4, p. 1229-1253, Dez 2014.

NORMAN, D. Design Emocional. Curitiba: Rocco, 2008.

O'GRADY, J. V.; O'GRADY, K. V. The Information Design Handbook. $1^{\text {a }}$. ed. Blue Ash: HOW Books, 2008.

PETTERSON, R. It depends: ID-principles and guidelines. Institute for Infology. Tullinge. 2012.

PRATES, R. O.; BARBOSA, S. D. J. Introdução à Teoria e Prática da Interação Humano Computador fundamentada na Engenharia Semiótica. Jornadas de Atualização em Informática - JAI, Florianópolis, 2007. 263-326. 
PREECE, J.; SHARP, H.; ROGERS, Y. Design de

Interação: Além da interação humano-

computador. [S.I.]: Bookman, 2013.

REPÚBLICA, P. D. Convenção sobre os direitos das pessoas com deficiência. Presidência da República, 2007. Disponível em: <https://bit.ly/3Fdvwms>. Acesso em: 08 abr. 2021.

REPÚBLICA, P. D. Presidência da República. VII Reunião do Comitê de Ajudas Técnicas, 2007. Disponível em: <https://bit.ly/328jlsY>. Acesso em: 08 abr. 2021.

REPÚBLICA, P. D. Lei Brasileira de Inclusão da Pessoa com Deficiência (Estatuto da Pessoa com Deficiência).

Presidência da República, 2015. Disponível em:

<https://bit.ly/3Fbzex6>. Acesso em: 02 abr. 2021.

SAMSUNG. Samsung. Celular | Acessibilidade

| Samsung, 2021. Disponível em: <https://bit.

ly/3e5A9Df>. Acesso em: 02 abr. 2021.

SILVA, B. S. D.; ANDRADE, G. V. D. S.; PINTO, J. A. D. S. Análise de Simuladores e Tecnologias Assistivas que Apoiam o Designer Ver Como Daltônicos. Revista ErgoDesign \& HCl, Rio de Janeiro, v. 5, n. Especial, p. 116 - 128, 2017.

SILVA, C. F. D.; FERREIRA, S. B. L.; RAMOS, J. F. M. Acessibilidade do WhatsApp sob a perspectiva de pessoas com deficiência visual. XV Simpósio Brasileiro sobre Fatores Humanos em Sistemas Computacionais (IHC), São Paulo, Out 2016.

TÉCNICAS, C. D. A. Tecnologia

Assistiva. Brasília: CORDE, 2009.

TRELLO. Trello Labels: How To Organize, Categorize, and Prioritize Your Cards. Blog Trello, 2020. Disponível em: <https://bit.ly/32d7NEJ>. Acesso em: 08 abr. 2021. 
UNIVERSITY, S. Design Thinking

Bootleg. Palo Alto: [s.n.], 2018.

VILLON, E. Cores e Comunicação: Barreiras

para daltônicos na Era Digital. Universidade de

São Paulo - Escola de Comunicações e Artes. São

Paulo, p. 49. 2019. WINDOWS. Acessibilidade no

Windows 10. Windows, 2019. Disponível em: <https://

bit.ly/3p6clWg>. Acesso em: 21 maio 2021.

WINDOWS. Auxílio e aprendizado do Windows.

Windows, 2021. Disponível em: <https://bit.

ly/30lvgNw>. Acesso em: 02 abr. 2021.

WINDOWS. Facilitar a visualização do Windows.

Windows, 2021. Disponível em: <https://bit.

ly/3Ee8D0R>. Acesso em: 02 04' 2021.

WINDOWS. Suporte de acessibilidade para

Windows. Windows, 2021. Disponível em: <https://

bit.ly/33Hmkcl>. Acesso em: 02 abr. 2021. 